\title{
(स)
}

INSTITUTO DE PESQUISAS ENERGÉTICAS E NUCLEARES

Autarquia Associada à Universidade de São Paulo

Caracterização dos pacientes portadores de câncer de próstata, atendidos em hospital de referência do estado do Tocantins - aptos à braquiterapia?

ANDRÉ DE SOUZA BEZERRA

Dissertação apresentada como parte dos requisitos para obtenção do Grau de Mestre em Ciências na Área de Tecnologia Nuclear - Aplicações

Orientador:

Prof. Dr. Carlos Alberto Zeituni

São Paulo

2021 
INSTITUTO DE PESQUISAS ENERGÉTICAS E NUCLEARES

Autarquia Associada à Universidade de São Paulo

Caracterização dos pacientes portadores de câncer de próstata, atendidos em hospital de referência do estado do Tocantins - aptos à braquiterapia?

Versão Corrigida

Versão Original disponível no IPEN

ANDRÉ DE SOUZA BEZERRA

Dissertação apresentada como parte dos requisitos para obtenção do Grau de Mestre em Ciências na Área de Tecnologia Nuclear - Aplicações

Orientador:

Prof. Dr. Carlos Alberto Zeituni 
Autorizo a reprodução e divulgação total ou parcial deste trabalho, para fins de estudo e pesquisa, desde que citada a fonte

Como citar:

BEZERRA, A. D. S. Caracterização dos pacientes portadores de câncer de próstata, atendidos em hospital de referência do estado do Tocantins - aptos à braquiterapia?. 2021. 53 p. Dissertação (Mestrado em Tecnologia Nuclear), Instituto de Pesquisas Energéticas e Nucleares, IPEN-CNEN/SP, São Paulo. Disponível em: (data de consulta no formato: dd/mm/aaaa)

Ficha catalográfica elaborada pelo Sistema de geração automática da Biblioteca IPEN/USP, com os dados fornecidos pelo(a) autor(a)

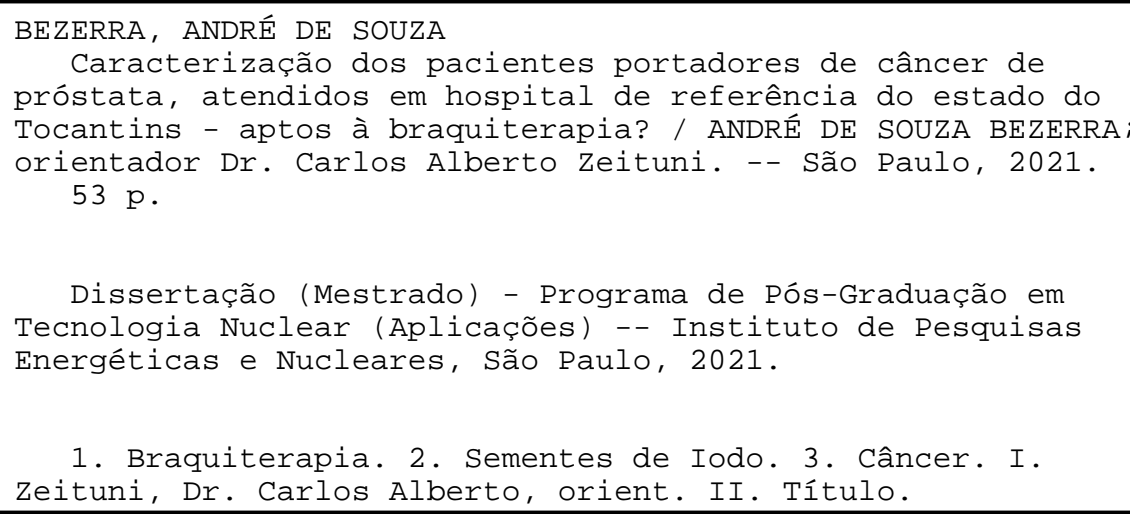


FOLHA DE APROVAÇÃO

André de Souza Bezerra

\section{Caracterização dos pacientes portadores de câncer de próstata, atendidos em hospital de referência do estado do Tocantins - aptos à braquiterapia?}

Dissertação apresentada como parte dos requisitos para obtenção do Grau de Mestre em Ciências na Área de Tecnologia Nuclear Aplicações.

Data: 05 / abr / 2021.

\section{Banca Examinadora}

Prof. Dr.: Carlos Alberto Zeituni

Instituição: IPEN / USP Julgamento: Aprovado

Prof. Dr.: Dib Karam Junior

Instituição: EACH / USP Julgamento: Aprovado

Prof. Dr.: Angélica Tamião Zafalon

Instituição: SENAC / SP Julgamento: Aprovado

Prof. Dr.:

Instituição: Julgamento:

Prof. Dr.:

Instituição: Julgamento:

Prof. Dr.:

Instituição: Julgamento: 
"Não pode ser coincidência que os melhores médicos sejam pessoas humildes, serenas e bem resolvidas. Evitem os pretensiosos, porque eles, na ânsia irrefreável de aparentar, gastam toda a energia imprescindível para ser. E ficam assim, vazios." 


\section{AGRADECIMENTOS}

Aos meus pais, Hilda e Raimundo, por todo o esforço que fizeram para nos dar as melhores condições possíveis de ensino, por se fazerem presentes apesar da distância, e por todo amor que nos deram. Por nos transmitirem o gosto pelos estudos e possibilitar as oportunidades que infelizmente não tiveram.

À minha amada família, meu refúgio de todas as horas e para onde sempre quero voltar.

À minha amada esposa Fernanda e nossos filhos José Antônio e Elisa, por todo amor que sinto por vocês, por todo incentivo e compreensão. Estão sempre em meus pensamentos.

Ao professor Carlos Alberto Zeituni, por aceitar o convite, além da paciência, dedicação e compromisso. Muitíssimo obrigado pelas orientações, apoio, ensinamentos ao longo do trabalho, e amizade que me permitiram concluir esse sonho.

À professora Maria Elisa Chuery Martins Rotelato pela imensa bondade, paciência, sabedoria, humildade e colaboração. Com a senhora, já são quatro os anjos em minha vida por nome de Elisa. Os outros são minha querida avó (in memoriam), a tia Elisa e minha pequena caçulinha.

Vocês foram minha inspiração. Guardarei a amizade e gratidão para sempre.

\section{Ao Instituto Tocantinense Antônio Carlos Porto - Porto Nacional I} grupo Afya que permitiram esse trabalho ao firmar o convênio de pós-graduação com o IPEN (Instituto de Pesquisa Energéticas e Nucleares) / Universidade de São Paulo. Por todo apoio e compreensão para pudéssemos conciliar esse projeto às nossas atividades docentes.

Aos amigos André Sena, Fernando Moreira e Lanuze Tavares por estarem sempre conosco nos incentivando e ajudando a tomar as melhores decisões durante o trabalho. Por me ajudarem a manter o foco e objetivo.

A todos os professores do IPEN (Instituto de Pesquisa Energéticas e Nucleares) que estiveram conosco durante as disciplinas, por nos inspirarem, em especial à Dra. Nanci do Nascimento (in memoriam). 
Aos funcionários do centro de ensino e pesquisa do Hospital Geral Público de Palmas pelo acolhimento caloroso, atenção e apoio para que esta pesquisa pudesse ser desenvolvida.

Aos nossos pacientes. 


\section{RESUMO}

BEZERRA, André de Souza. Caracterização dos pacientes portadores de câncer de próstata, atendidos em hospital de referência do estado do Tocantins - aptos à braquiterapia? 2020. 53p. Tese (Mestrado em Tecnologia Nuclear) - Instituto de Pesquisas Energéticas e Nucleares - IPEN - CNEN/SP, São Paulo.

A observação e identificação dos fatores preditores de resultados e morbidade são essenciais na seleção ideal de pacientes que podem utilizar a braquiterapia como modalidade de tratamento do câncer de próstata. É capaz de melhorar o controle tumoral, aliviar os sintomas associados à doença e, com isso, melhora a qualidade de vida de pacientes. O estado do Tocantins não oferece essa modalidade terapêutica, disponibiliza apenas tratamento por cirurgia, terapia hormonal ou radioterapia externa convencional, sem conseguir atender toda a demanda. O objetivo desta pesquisa é analisar a população de pacientes portadores de câncer de próstata atendidos no Hospital Geral Público de Palmas no ano de 2015, verificar quantos estariam aptos à braquiterapia e analisar o impacto caso ela pudesse ser ofertada. O método empregado foi quantitativo, com as características de uma análise retrospectiva, transversal e descritiva. Realizado na maior unidade de saúde estadual, o Hospital Geral Público de Palmas, apesar de suas grandes dimensões, convive com os principais problemas do Sistema Único da Saúde, como superlotação e desabastecimento. Verificou-se que a maior parte dos pacientes atendidos correspondia à idade de 70 a 79 anos, perfazendo um total de $45 \%$. Predominantemente eram do estado do Tocantins, mas alguns moravam em outros estados (Pará). Os dados relacionados ao escore de Gleason mostraram que houve uma predominância dos níveis 6 e 7, indicando tumores de grau baixo/intermediário. Os pacientes analisados apresentaram estadiamento predominante II e III do CaP, e que $36,11 \%$ deles estavam aptos à braquiterapia. A aplicação deste método impactaria positivamente reduzindo a demanda por leitos, internações e consultas ambulatoriais, possibilitando mais 52 dias/leito disponíveis ao HGPP ao ano, reduziria os custos com tratamento fora de domicílio, permitiria a reabilitação precoce, além de contribuir para a descentralização do serviço.

Palavras-chave: Braquiterapia; Sementes de Iodo; Câncer. 


\begin{abstract}
BEZERRA, André de Souza. Characterization of patients with prostate cancer, seen at a referral hospital in the state of Tocantins - able to brachytherapy? 2020. 53p. Tese (Mestrado em Tecnologia Nuclear) - Instituto de Pesquisas Energéticas e Nucleares - IPEN - CNEN/SP, São Paulo.
\end{abstract}

Observation and identification of predictive factors for results and morbidity are essential in the ideal selection of patients who can use brachytherapy as a treatment modality for prostate cancer. It is capable of improving tumor control, relieving symptoms associated with the disease and, thereby, improving the quality of life of patients. The state of Tocantins does not offer this therapeutic modality, it only offers treatment by surgery, hormonal therapy or conventional external radiotherapy, without being able to meet all the demand. The objective of this research is to analyze the population of patients with prostate cancer treated at the Hospital Geral Público de Palmas in 2015, to verify how many would be able to brachytherapy and to analyze the impact if it could be offered. The method used was quantitative, with the characteristics of a retrospective, cross-sectional and descriptive analysis. Held in the largest state health unit, the Hospital Geral Público de Palmas, despite its large dimensions, lives with the main problems of the Unified Health System, such as overcrowding and shortages. It was found that most of the patients seen were aged between 70 and 79 years, making a total of $45 \%$. Most were from the state of Tocantins, but some lived in other states (Pará). The data related to the Gleason score showed that there was a predominance of levels 6 and 7 indicating low / intermediate grade tumors. The analyzed patients had a predominant staging of $\mathrm{CaP}$ II and III, and that $36.11 \%$ of them were able to undergo brachytherapy. The application of this method would positively impact by reducing the demand for beds, hospitalizations and outpatient consultations, allowing an additional 52 days / bed available to the HGPP per year, reducing the costs of treatment outside the home, allowing early rehabilitation, in addition to contributing to the decentralization of the patient. service.

Keywords: Brachytherapy; Lodine seeds; Cancer. 


\section{LISTA DE GRÁFICOS}

Gráfico 1 - Faixa de idade dos pacientes analisados .................................... 32

Gráfico 2 - Local de origem e número de pacientes analisados ..........................33

Gráfico 3 - Tempo entre o diagnóstico e o início do tratamento dos pacientes

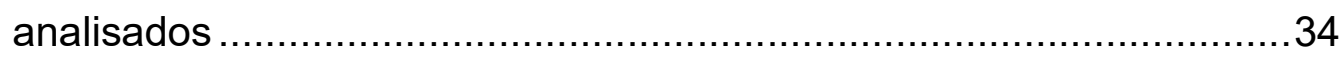

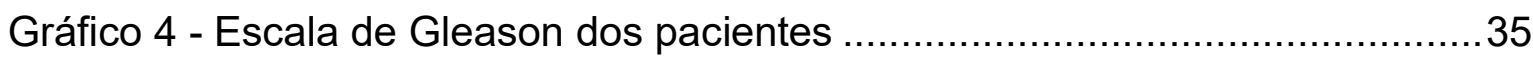

Gráfico 5 - Grau de estadiamento da amostra desta pesquisa .........................38

Gráfico 6 - Tipos de tratamentos realizados ............................................... 39

Gráfico 7 - Local de tratamento dos pacientes analisados...............................42

Gráfico 8 - Aptidão dos pacientes à Braquiterapia ...........................................43 


\section{LISTA DE FIGURAS}

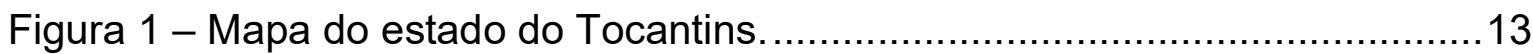

Figura 2 - Vista lateral da próstata com destaque à sua localização. ...................18

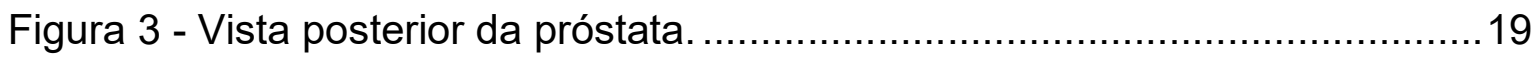

Figura 4 - Representação da glândula prostática com câncer ...............................20

Figura 5 - Distribuição proporcional dos 10 tipos de câncer mais incidentes estimados para 2020 por sexo, exceto pele não melanoma - números arredondados para múltiplos de $10 \ldots \ldots \ldots \ldots \ldots \ldots \ldots \ldots \ldots \ldots \ldots \ldots \ldots \ldots \ldots \ldots . . .21$

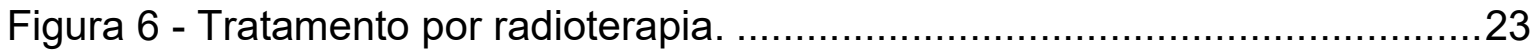

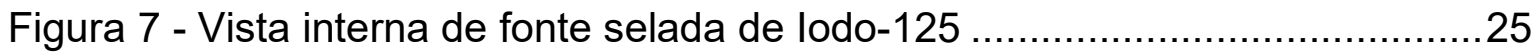

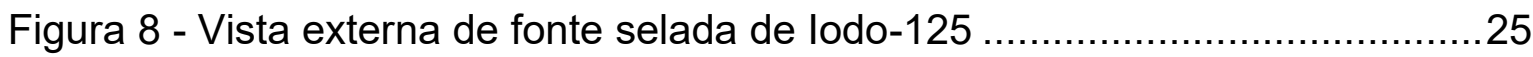

Figura 9 - Posicionamento e implante de sementes radioativas na próstata. .......26

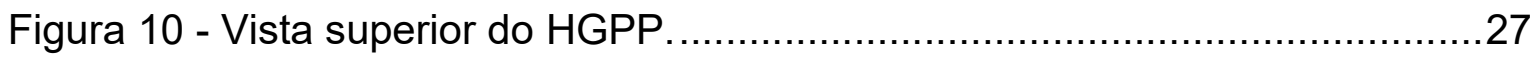

Figura 11 - Aparelho de radioterapia do Hospital Geral de Araguaína...................29

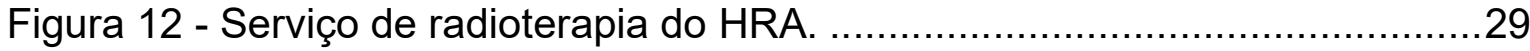

Figura 13 -Escala de Gleason para a classificação histológica do adenocarcinoma

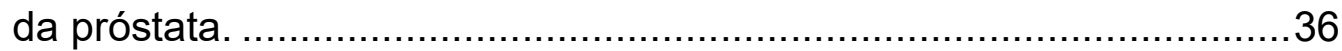

Figura 14 - A classificação Tumor Nodo Metástase (TNM)...................................41 


\section{SUMÁRIO}

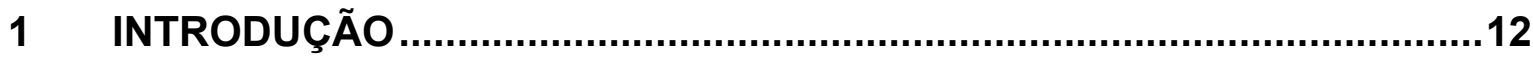

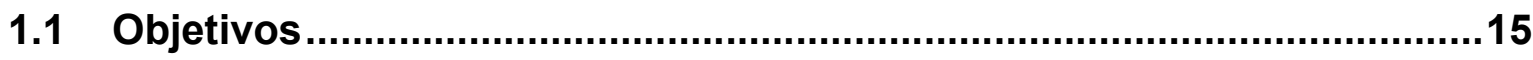

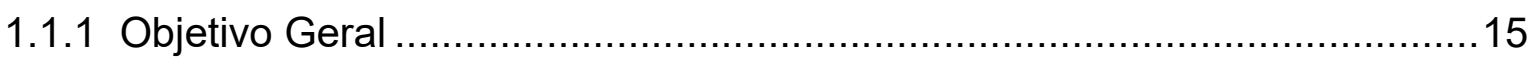

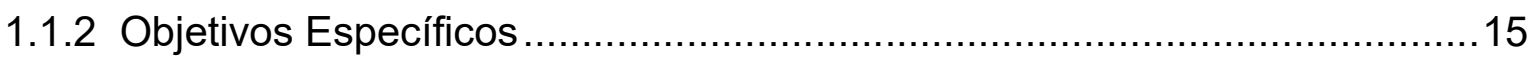

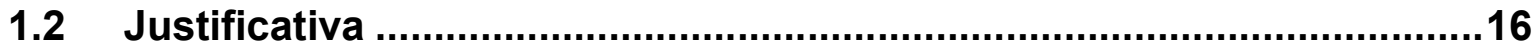

2 REVISÃO DE LITERATURA ........................................................18

2.1 Anatomia e fisiologia da próstata ........................................................18

2.2 Sintomas e epidemiologia do CaP .....................................................20

2.3 Diagnóstico e tipos de tratamento do CaP .........................................22

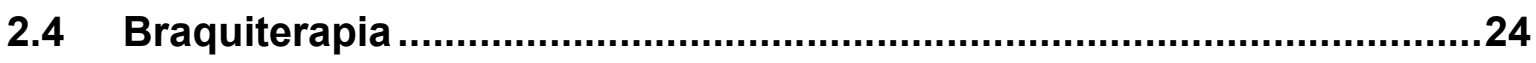

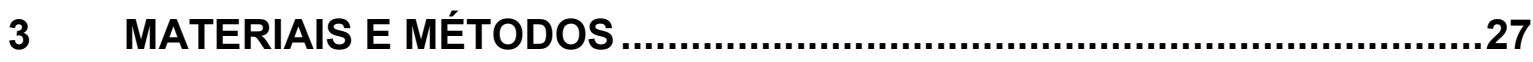

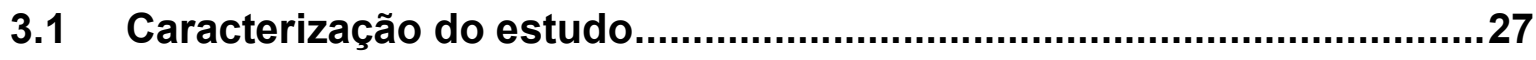

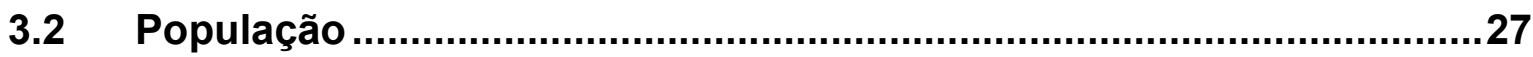

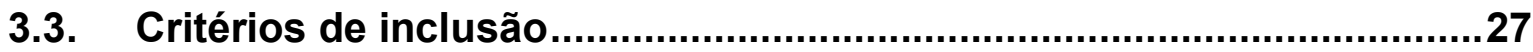

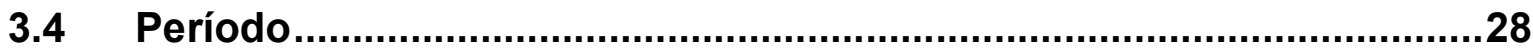

3.5 Área de estudo ...........................................................................28

3.6 Procedimentos e análise estatística...................................................30

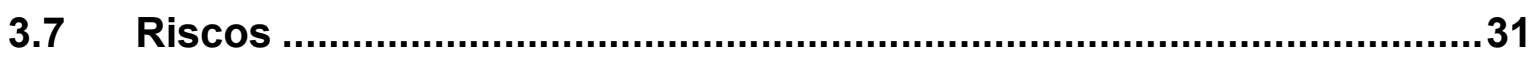

3.8 Critérios de paralisação ou encerramento da pesquisa ........................31

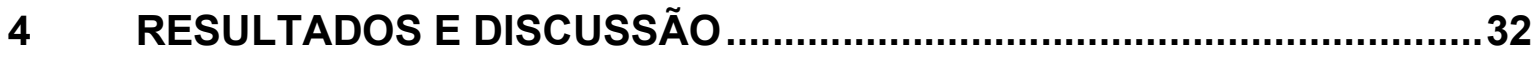

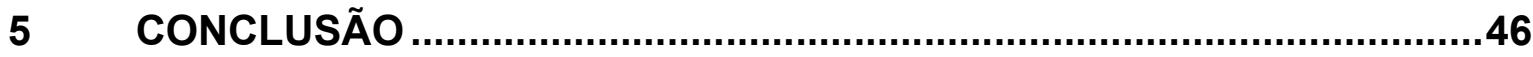

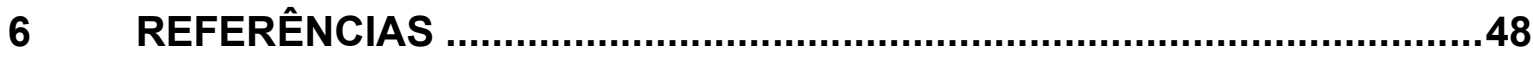

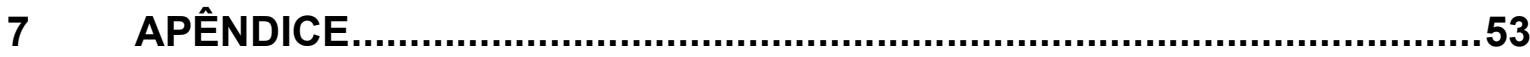




\section{INTRODUÇÃO}

O câncer de próstata é o tumor mais frequente em homens em todas as regiões do país, representando $29 \%$ dos casos diagnosticados, com exceção aos tumores de pele não-melanoma (INCA, 2020). Um aumento acentuado da incidência tem sido verificado em virtude dos programas seriados de detecção em pacientes assintomáticos, o que permitiu também que os novos casos fossem diagnosticados, na sua maioria, em fases iniciais da doença. A estimativa americana é de que aproximadamente $90 \%$ dos casos sejam diagnosticados na fase de tumor localizado, com taxas de sobrevida em cinco anos de $100 \%$ (JEMAL et al., 2007).

Dados do Instituto Nacional do Câncer (INCA, 2020) indicam que para 65.840 novos casos de câncer de próstata a cada ano no Brasil, entre 2020 e 2022. Homens com mais de 50 anos, raça negra, com excesso de peso e obesidade, estão mais propensos à doença.

Todavia muitos destes casos apresentarão prognóstico ruim devido às dificuldades de acesso dos usuários de serviços públicos de saúde e a precariedade de muitos destes. Este cenário é determinante para a ocorrência de muitos casos de doença em fase avançada, diagnósticos tardios, condição clínica ruim e ao maior risco de óbito (BRAGA et al., 2017).

O estado do Tocantins possui estrutura de saúde limitada, no que se refere a capacidade operacional, caracterizada pela centralização de serviços oncológicos e cirúrgicos. Em relação ao tratamento do câncer de próstata, o estado dispõe de cirurgia, radioterapia externa e da terapia hormonal, mas infelizmente ainda não oferece a possibilidade de tratamento braquiterápico.

A braquiterapia consiste no implante de fontes radioativas seladas em forma de sementes contendo radioisótopo iodo-125 junto ao tumor, fazendo com que a região alvo do tratamento receba elevada dose de radiação, preservando os tecidos circunvizinhos saudáveis (SOUZA, 2012). 
Figura 1: Mapa do estado do Tocantins

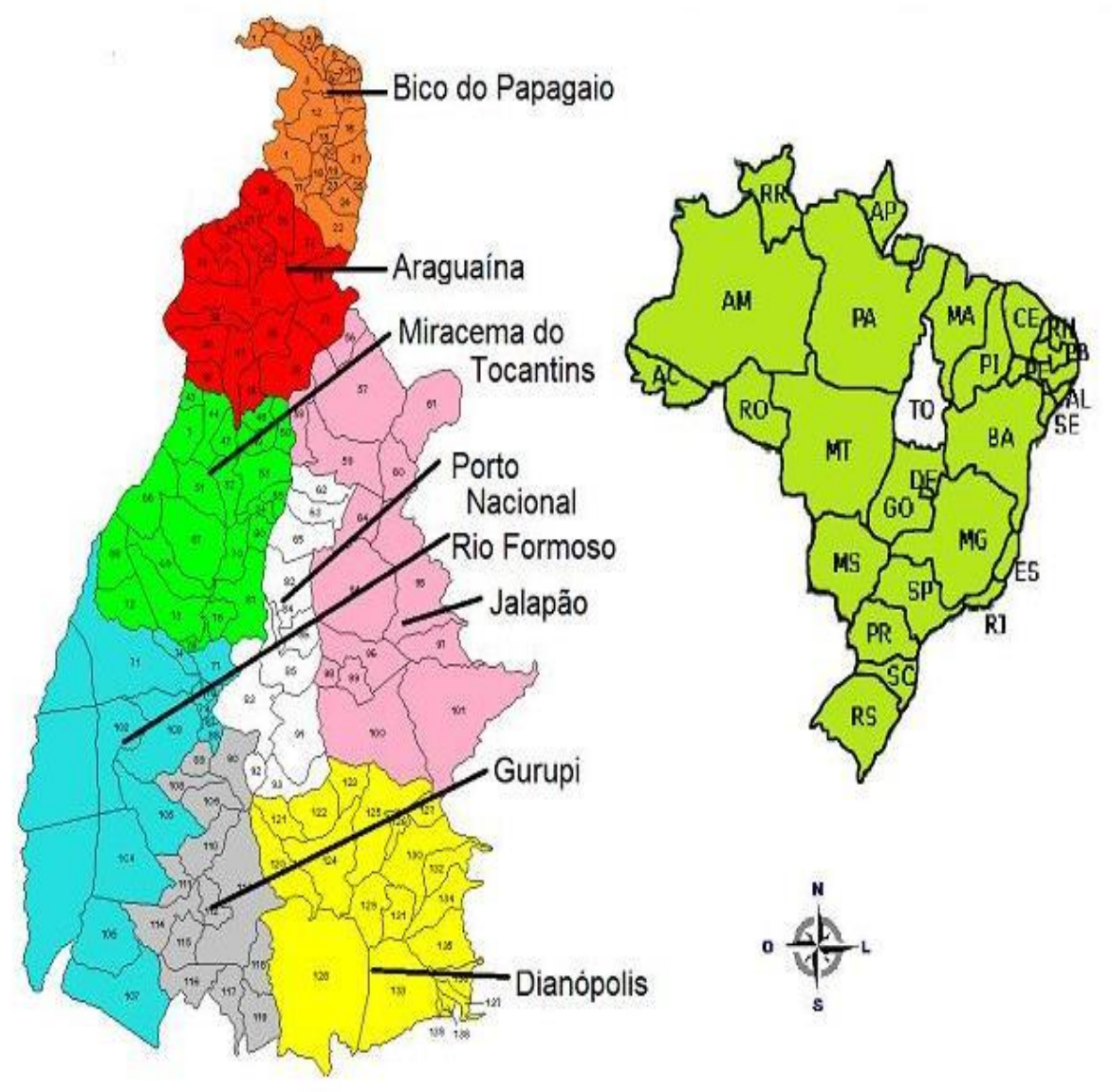

Fonte: researchgate.net/figure

A população do estado é de 1.590.248 habitantes, segundo dados do IBGE, distribuída em 129 municípios, alguns a mais de 700 quilômetros da capital. Toda a amostra de pacientes é referenciada a apenas duas cidades e precisam lidar com uma expectativa de tratamento bastante demorado, pois a cirurgia (prostatectomia radical) e terapia hormonal apenas são realizados em dois hospitais da rede estadual, enquanto a radioterapia apenas no Hospital Regional de Araguaína (HRA), cidade localizada no extremo norte do estado, a 400 quilômetros da capital, Palmas.

Além disto, a infraestrutura para o enfrentamento desse tipo de câncer é incapaz de atender à demanda e muitos indivíduos buscam tratamento em outros estados. Aos que ficam, resta conviver com a realidade de hospitais sobrecarregados e a demora na fila de espera para tratamento. 
O Hospital Geral Público de Palmas é a maior unidade hospitalar do estado, referência para tratamento desse tipo de câncer inclusive para vários municípios de estados vizinhos, da região sudeste da Amazônia legal. Entretanto, dispõe de cerca de 8 leitos urológicos a serem divididos entre doenças benignas, urgências urológicas e outros tipos de câncer, e, contraditoriamente, por vezes precisa encaminhar seus pacientes para outros estados.

A radioterapia também é uma modalidade de tratamento capaz de promover a cura da doença, melhorar o controle tumoral e a qualidade de vida dos pacientes. Um dos principais avanços nesta área foi a utilização da radioterapia guiada por imagem, que permitiu otimizar a radiação no ponto exato do câncer, preservando tecidos vizinhos saudáveis - IGRT (SANDRINI et al., 2014).

Este tipo de tratamento é realizado apenas na cidade de Araguaína, que devido às constantes interrupções do serviço por problemas técnicos no equipamento ou falta de equipe multiprofissional apta, obriga por vezes a necessidade de referenciamento dos pacientes a estados vizinhos como Maranhão e Goiás. Existe uma previsão de ampliação da sua capacidade de atendimentos, com a instalação de outro acelerador linear, ainda sem data definida. 


\subsection{Objetivos}

\subsubsection{Objetivo Geral}

Caracterizar os pacientes portadores de câncer de próstata, atendidos em hospital de referência do estado do Tocantins, no ano de 2015.

\subsubsection{Objetivos Específicos}

$\checkmark$ Determinar quantos dos pacientes, com câncer de próstata no HGPP, poderiam ter sido tratados através da braquiterapia, evitando assim que eles fossem conduzidos por outros métodos como a cirurgia ou radioterapia, o que poderia significar demasiada espera para tratamento, piora no prognóstico da doença e aumento da possibilidade de efeitos indesejáveis do tratamento, como a disfunção erétil e incontinência urinária.

$\checkmark$ Detalhar as características destes indivíduos como o seu perfil epidemiológico, procedência, estadiamento clínico no momento do diagnóstico, tipos de tratamentos aos quais foram encaminhados, tempo entre diagnóstico e início do tratamento. São dados importantes para que possamos verificar as condições em que os pacientes entraram no Sistema Único de Saúde, se com doença localizada ou avançada, se houve longa espera pelo tratamento e fatores que possam ter prejudicado o sucesso terapêutico. Esses aspectos conseguem demonstrar o alinhamento e efetividade das ações aplicadas para detecção e rastreio populacional da doença com a conclusão do tratamento, pois é evidente a necessidade de diagnóstico precoce e rápida abordagem para um desfecho favorável.

$\checkmark$ Analisar as possíveis repercussões para a dinâmica de funcionamento do Hospital Geral Público de Palmas, no que se refere ao tratamento desta patologia, caso fosse disponibilizada a braquiterapia. Se seria possível a otimização dos leitos, redução de custos ao Sistema Único de Saúde estadual, diminuição da demanda por leito e da fila de espera por internamento, redução das consultas e reinternações. 
$\checkmark$ Analisar o impacto da braquiterapia no aspecto da logística e fluxo de pacientes frente a uma realidade atual que exige longos deslocamentos dos pacientes para concluir seu tratamento, muitas vezes dificultado pela falta de leitos e interrupções do único serviço público de radioterapia existente no estado, obrigando em algumas a serem encaminhados a estados vizinhos.

\subsection{Justificativa}

A natureza da doença oncológica prostática requer brevidade na condução do tratamento, ou então todo o esforço em campanhas para deteç̧ão precoce irá se diluir, comprometendo o sucesso da terapia.

O tratamento braquiterápico é uma modalidade terapêutica praticada em todo o mundo desde o século XX e já replicada em alguns estados brasileiros. Adquiriu respeito por demonstrar bons resultados oncológicos e baixa morbidade, quando adequadamente indicada. Apresenta vantagens como poder ser realizada ambulatorialmente, dispensando a necessidade de leito e internação hospitalar prolongada, e permite retorno precoce às atividades dos pacientes.

Vivemos em um contexto de pandemia pela COVID 19 desde o início de 2020 que produziu graves impactos ao funcionamento dos serviços de saúde, públicos e privados, realidade ainda sem perspectivas de um controle breve. A sobrecarga de doentes tem produzido lotações dos hospitais, mesmos com após leitos criados, esgotamento dos insumos hospitalares como sedativos e relaxantes musculares, reordenamento de prioridades e suspensão de tratamentos eletivos, incluindo os tratamentos oncológicos. Se antes desse cenário já se convivia com filas de espera para tratamento, após a crise sanitária do novo Coronavírus já se aguarda por uma crise em outras áreas da saúde que tiveram suas demandas reprimidas.

Em uma estrutura sobrecarregada como a do estado do Tocantins, que serve também de referência para municípios de outros estados da região sudeste da Amazônia legal, é de fundamental importância a oferta de novas modalidades terapêuticas, que aperfeiçoem a utilização dos escassos recursos da saúde pública e possibilite mais acesso aos pacientes. A produção de trabalhos sobre 
esse tema fundamenta e abre caminho para as melhores decisões de investimentos pelos gestores dessa área da saúde.

Por isso, é importante esclarecer o impacto que a implantação da braquiterapia pode representar para a realidade da saúde pública estadual, não apenas quanto ao custeio primário, mas também na logística dos tratamentos, nas possíveis melhorias quanto a acessibilidade, fluxo e demanda de pacientes, na diminuição dos deslocamentos e redução do tempo entre diagnóstico e terapia implementada. 


\section{REVISÃO DE LITERATURA}

\subsection{Anatomia e fisiologia da próstata}

A próstata é uma glândula que compreende o segmento mais proximal da uretra. Anatomicamente, a próstata situa-se na pelve verdadeira, separada anteriormente da sínfise púbica pelo espaço retropúbico (Retzius). A superfície posterior da próstata está afastada da ampola retal pela fáscia de Denonvilliers. A base da próstata tem continuidade no colo da bexiga e o ápice repousa sobre a superfície superior do diafragma urogenital (CLAUS; JOHN, 2002; LEZE, 2014).

Lateralmente, a próstata se relaciona com a musculatura elevadora do ânus. Foi publicado por McNeal o conceito de anatomia zonal da próstata onde foram identificadas três zonas distintas (FIGURA 1).

Figura 2 - Vista lateral da próstata com destaque à sua localização.

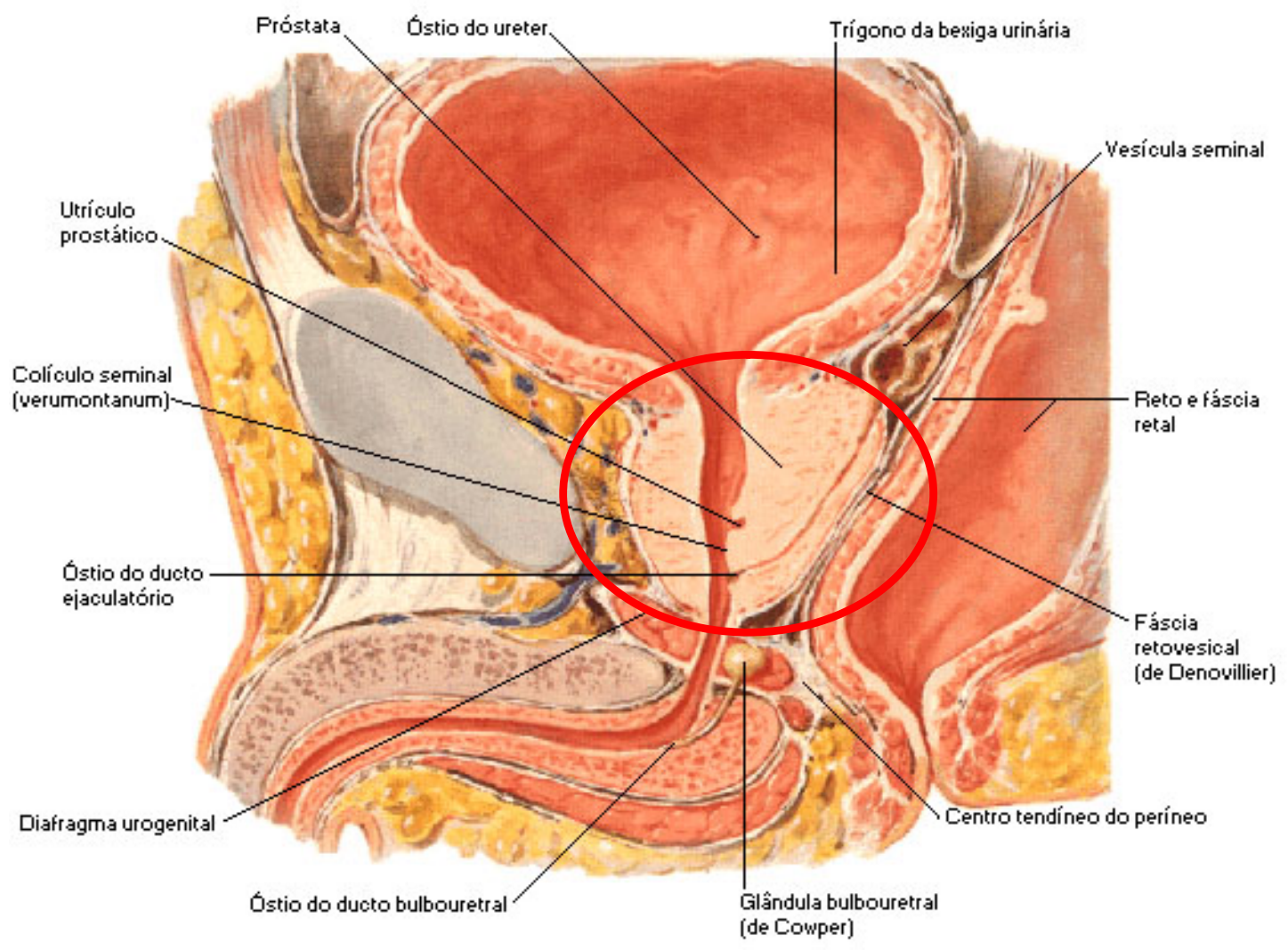

Fonte: AULA DE ANATOMIA (2020) 
A zona periférica representa $70 \%$ do volume prostático no adulto jovem, a zona central representa $25 \%$, e a zona de transição, $5 \%$. De 60 a $70 \%$ dos carcinomas de próstata têm origem na zona periférica, 10 a $20 \%$ na zona de transição e 5 a $10 \%$ na zona central. A hiperplasia prostática benigna origina-se uniformemente na zona de transição, acometendo também a zona periuretral (TANAGHO; MCANINCH, 2010). A Figura 2 apresenta a vista frontal da próstata.

Figura 3 - Vista posterior da próstata.

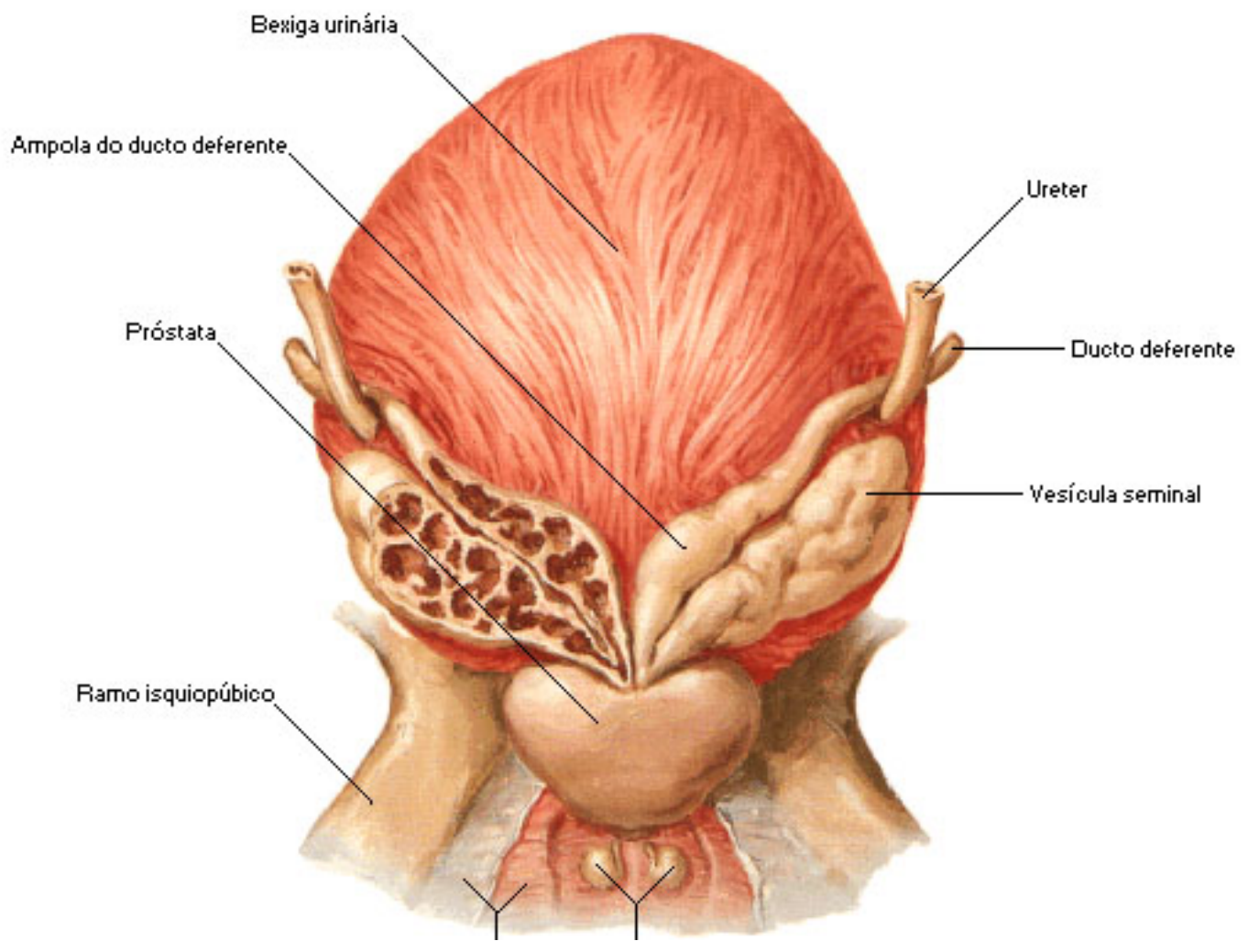

Fonte: AULA DE ANATOMIA (2020)

A próstata é um órgão sexual acessório que produz substâncias fundamentais de natureza alcalina para a eficácia do esperma, na fertilização dos óvulos, no trato reprodutivo feminino. É capaz de produzir, através das células neuroendócrinas, peptídeos como a somatostatina, calcitonina e neurotensina (LEZE, 2011).

A função da próstata está relacionada com a produção do líquido prostático, uma secreção clara e fluida. Este líquido fornece os nutrientes necessários para os espermatozoides, que por sua vez são produzidos nos testículos. Esse fluido apresenta $\mathrm{pH}$ alcalino e sua composição é formada por 
açúcares simples, representando assim entre 10 e $30 \%$ do volume de todo líquido seminal. Apresenta também proteínas que correspondem a $1 \%$ de sua composição, além de abranger enzimas proteolíticas e antígenos específicos, zinco e fibrinolisina, que ajudam a dissolver o sêmen (CLAUS; JOHN, 2002).

Para desenvolver sua função, a próstata precisa dos hormônios masculinos, chamados de andrógenos. O principal hormônio masculino é a testosterona, responsável pelo crescimento prostático. As células luminais produzem parte do plasma seminal, incluindo o PSA - a fosfatase ácida prostática (CLAUS; JOHN, 2002).

\subsection{Sintomas e epidemiologia do CaP}

O CaP é uma doença neoplásica, causada pela proliferação de células de maneira desordenada e histologicamente com vários graus de diferenciação celular e comportamento histológico anárquico (ZIADA; ROSENBLUM; CRAWFORD, 1999; CARNEVALE, 2010). A Figura abaixo apresenta a glândula prostática com câncer.

Figura 4 - Representação da glândula prostática com câncer

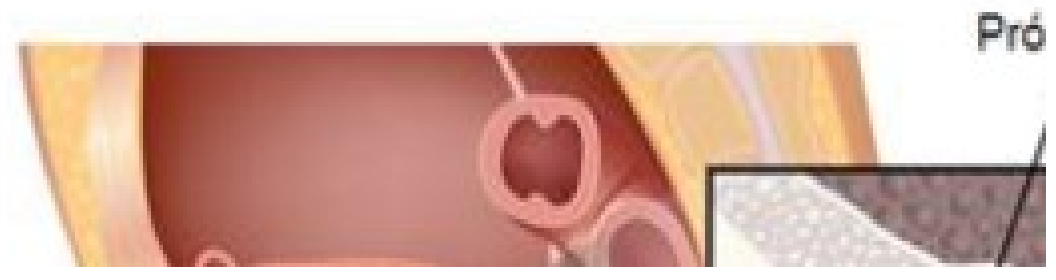

Fonte: RODRIGUES (2015).

A história natural desta patologia tende a ser assintomática e pouco perceptível inicialmente, só sendo detectada através de exames de rastreamento populacional. Com o passar do tempo, podem surgir sintomas locais como alteração do padrão miccional, hemorragias urinárias, retenção miccional e impacto na qualidade de vida, e a longo prazo surgem os sintomas relacionados à 
disseminação para outros locais do organismo, o que é conhecido como metástases. Em casos severos pode ocasionar alteração irreversível da estrutura da bexiga, sepse, insuficiência renal e até morte (ZIADA; ROSENBLUM; CRAWFORD, 1999; CARNEVALE, 2010).

Esta fase é causada pelo desenvolvimento de focos tumorais à distância da lesão primária, e isso ocorre mais frequentemente nos tecidos circunvizinhos como vesículas seminais, ureter e também nos ossos da coluna lombo-sacral e bacia pélvica. O diagnóstico da doença é feito através da biópsia e posterior estudo histopatológico de doze pequenos fragmentos, confirmando as alterações celulares cancerígenas e quantificando aspectos de diferenciação e agressividade, além de fazer o diagnóstico diferencial com outras patologias inflamatórias e neoplasias benignas (CLAUS; JOHN, 2002).

De acordo com a Organização Mundial da Saúde, o câncer de próstata é o segundo em incidência no homem e a sexta causa de morte mais frequente na população masculina mundial. No Brasil, estimam-se 65.840 casos novos de câncer de próstata para cada ano do triênio 2020-2022. Esse valor corresponde a um risco estimado de 62,95 casos novos a cada 100 mil homens, conforme a Figura 4 (INCA, 2020).

Figura 5 - Distribuição proporcional dos 10 tipos de câncer mais incidentes estimados para 2020 por sexo, exceto pele não melanoma - números arredondados para múltiplos de 10.

ropulaçao padrao munolal (1you). I 'Numeros arrecondados para mulijipios de iu.

\section{(FIGURA1)}

\section{Distribuiçãa proporcional dos dez tipos de câncer mais incidentes estimados para 202}

\section{Localização primária}

Próstata

Cólon e Reto
Casos

$65.840 \quad 29,2 \%$

$20.540 \quad 9,1 \%$ Homens

Fonte: INCA (2020). 
Desconsiderando os tumores de pele não melanoma, o câncer de próstata ocupa a primeira posição no país em todas as Regiões brasileiras, com um risco estimado de 72,35/100 mil na Região Nordeste; de 65,29/100 mil na Região Centro-Oeste; de 63,94/100 mil na Região Sudeste; de 62,00/100 mil na Região Sul; e de 29,39/100 mil na Região Norte (INCA, 2020).

\subsection{Diagnóstico e tipos de tratamento do CaP}

O CaP pode ser uma doença agressiva, sendo este um dos principais argumentos para se justificar o seu rastreamento. Mesmo com todas as pesquisas, não se conhece bem a sua história natural, mas nota-se um comportamento heterogêneo e na maioria dos casos a evolução é lenta, sendo o indivíduo assintomático durante a maior parte do tempo (MORI, 2016).

O aparecimento de um novo marcador, antígeno prostático específico (PSA), permitiu que o diagnóstico do carcinoma da próstata se fizesse em estadios bem mais precoces e em homens mais novos. Estes fatores ocasionaram profundas alterações na terapêutica da doença.

Desde então, a doença está frequentemente localizada no momento do diagnóstico; todavia, há, seguramente, um elevado número de pacientes em que o carcinoma é diagnosticado, mas que nunca virão a desenvolver a doença com significado clínico.

Este grupo de pacientes pode ficar sujeito a terapêuticas que provavelmente não necessitaria, e sofrer as morbidades delas. É o que chamamos de sobretratamento, assunto atual e motivo para grandes debates sobre os melhores critérios para se iniciar e escolher a modalidade de tratamento.

As terapêuticas curativas eficazes, aceitas pela comunidade científica na atualidade, são a prostatectomia radical, a radioterapia externa (teleterapia) e a radioterapia intersticial, também chamada de braquiterapia (JUNIOR, 2017). Perante uma eficácia aparentemente idêntica, é a maior ou menor morbidade que ditarão a escolha da terapêutica a aplicar (PINHEIRO, 2006).

O tratamento cirúrgico padrão é a prostatovesiculectomia radical (mais comumente chamada "prostatectomia radical"), onde se resseca a próstata, vesículas seminais, ampolas dos ductos deferentes e tecido periprostático, em bloco, associado ou não a linfadenectomia obturadora e ilíaca interna. Os 
principais efeitos colaterais de curto e longo prazo são: sangramento perioperatório com necessidade de hemotransfusão, fístula urinária, linfocele, hérnia incisional, disfunção erétil, incontinência urinária e estenose uretral (MORI, 2016; WILT, 2012).

A radioterapia externa ou teleterapia é o tipo mais utilizado, feito com feixe de radiação externo onde a próstata e os tecidos vizinhos são tratados por um feixe de radiação proveniente de um acelerador linear ou de outra fonte de radiação, como mostra a Figura 5 (LIMA, 2016).

Figura 6 - Tratamento por radioterapia.

\section{de um acelerador linear ou de outra fc}

\section{TRATAMENTO APÓS O DIAGNó Como é feito hoje}

Radioterapia

Exposiçāo a radiação ionizante

> Causa alteraçōes nas células. As malignas năo cionnrtam ne Hanne a

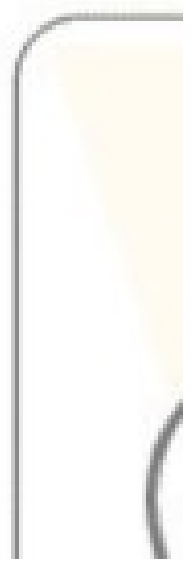

Fonte: LIMA (2016).

A radioterapia interna ou braquiterapia é bastante usada em estágios iniciais e intermediários da doença, consiste na introdução de sementes, fontes radioativas seladas, contendo o radioisótopo $125 \mathrm{I}$ ou 103Pd no interior do órgão, próximas ao tumor, afetando minimamente os órgãos circunvizinhos (LIMA, 2016).

Em termos de eficácia oncológica, os resultados são aparentemente similares para as três formas de terapêutica citadas. Neste sentido, é na morbidade e nos efeitos secundários ou no impacto sobre a qualidade de vida que 
as diferentes terapêuticas do carcinoma da próstata localizado se devem distinguir.

Neste contexto, e nos últimos 10 anos, tem-se assistido a uma evolução conceitual e efetiva do tratamento do carcinoma da próstata localizado, com o desenvolvimento de terapêuticas curativas cirúrgicas e não cirúrgicas. $O$ conceito filosófico de base a este progresso é o da mini-invasibilidade com o objetivo de baixar a morbilidade terapêutica mantendo a qualidade de vida dos pacientes, mas sem perder em eficácia oncológica. Acessoriamente, pretende-se diminuir o tempo de internamento hospitalar e o de inatividade profissional (COLÉGIO BRASILEIRO DE RADIOLOGIA, 2017).

\subsection{Braquiterapia}

Marta et al. (2011) apresenta que a braquiterapia vem sendo utilizada no CaP desde o começo deste século. Em 1917 foi apresentada como uma técnica promissora no Memorial Sloan Kettering Cancer Center em Nova lorque. Com o passar dos anos a técnica foi se desenvolvendo e sendo aperfeiçoada na América do Norte e Europa. A braquiterapia transperineal foi realizada pela primeira vez no Brasil em 1998 na cidade do Rio de Janeiro. Logo em seguida, outros serviços na cidade de São Paulo (Hospital Sírio-Libanês, Universidade Federal de São Paulo - Escola Paulista de Medicina, Hospital A. C. Camargo, Instituto Arnaldo Vieira de Carvalho, Hospital Israelita Albert Einstein), Campinas e Curitiba desenvolveram e implementaram a técnica onde se destacam até atualmente.

O CaP, quando precocemente diagnosticado, pode ser tratado por braquiterapia, na qual fontes de lodo-125 são implantadas permanentemente na próstata (SOUZA, 2018).

A braquiterapia é um tratamento clínico que consiste na aplicação de fontes radioativas seladas, chamadas de sementes (FIGURA 6). Depois de implantada, a fonte liberará a dose na região ou por um curto período de tempo (implantes temporários) ou até ocorrer o decaimento da fonte (implantes permanentes). É importante enfatizar que a dose recebida pelos tecidos adjacentes é significativamente reduzida, devido à localização estratégica da fonte dentro da lesão ou do órgão afetado (SOUZA, 2012; SOUZA, 2018). 
Figura 7 - Vista interna de fonte selada de lodo-125

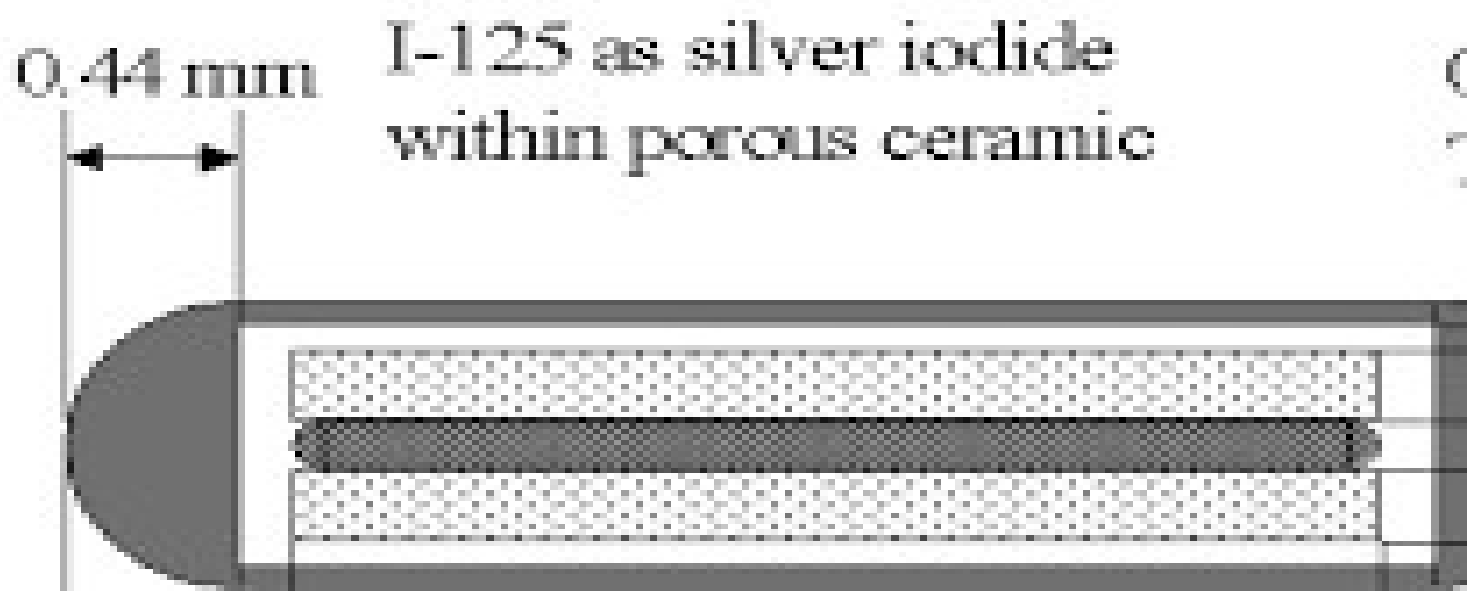

Fonte: LIMA (2016).

O tratamento do câncer de próstata por braquiterapia consiste na colocação das sementes radioativas em contato com o tumor (FIGURA 7). As doses de radiação são liberadas continuamente, durante o decaimento radioativo da fonte. Por isso, as sementes de iodo não causam complicações futuras e também pelo fato de que as cápsulas são seladas com um material biocompatível, o titânio (CAVALCANTI, 2017).

Figura 8 - Vista externa de fonte selada de lodo-125

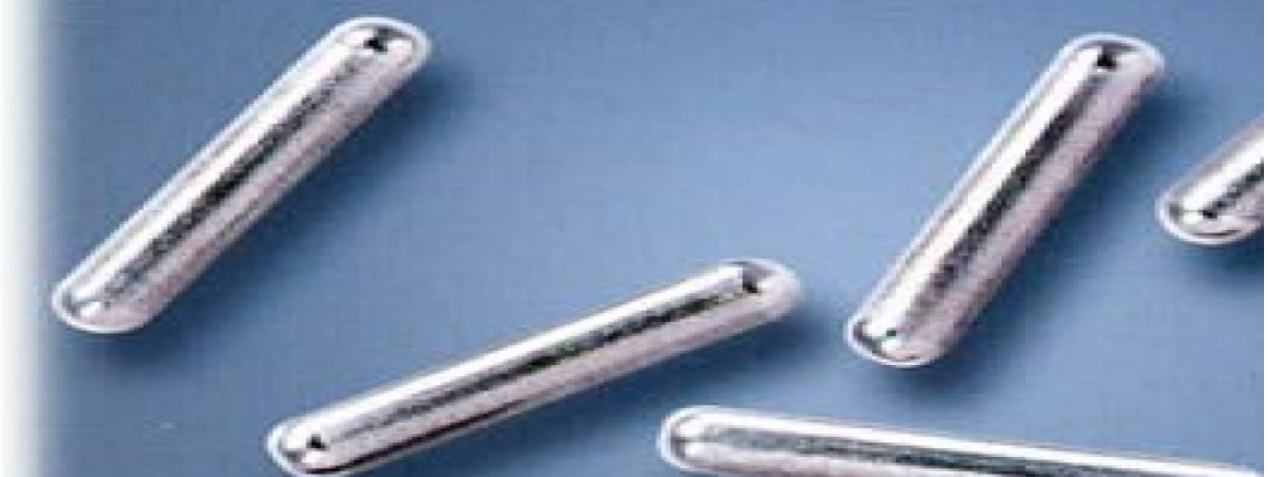

Fonte: ONCOFISIO (2016).

Lima (2016) observa que mesmo depois de dois anos de implantação (FIGURA 8), as sementes emitem baixíssimos níveis de radiação e a eficácia do tratamento é de aproximadamente $85-95 \%$ quando comparada aos tratamentos usuais (radioterapia e intervenções cirúrgicas).

As principais vantagens desse tipo de tratamento consistem na diminuição da dose fora da área do implante, preservação de tecidos sadios, 
menor incidência de efeitos colaterais como impotência e incontinência urinária, além da rápida recuperação (CAVALCANTI, 2017).

Figura 1 - Posicionamento e implante de sementes radioativas na próstata.

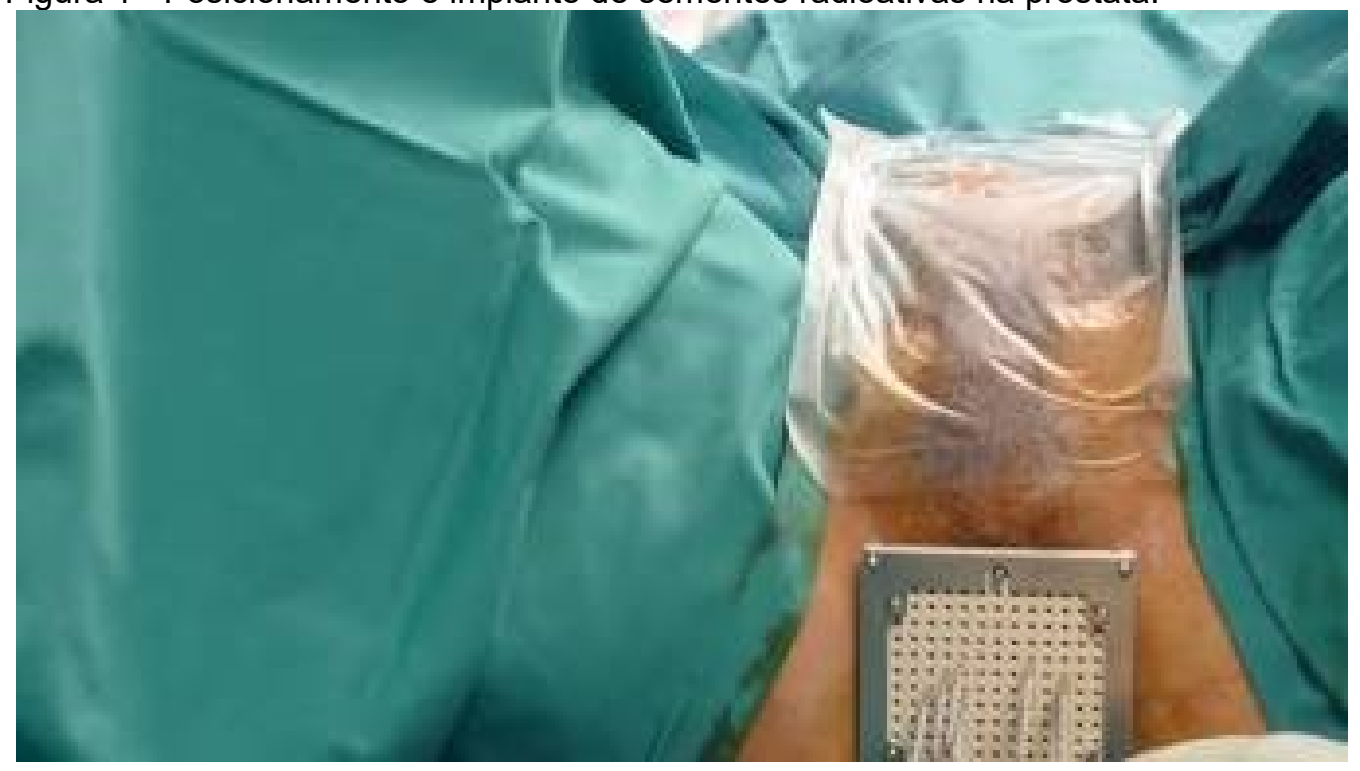

Fonte: ECURED, 2012.

Segundo Marta et al. (2011) mesmo com as vantagens da braquiterapia de próstata ela ainda é uma terapêutica totalmente subutilizada devido, principalmente, aos poucos serviços que detêm o conhecimento e capacitação técnica-científica e estrutural para realizar esse procedimento. 


\section{MATERIAIS E MÉTODOS}

\subsection{Caracterização do estudo}

Selecionou-se o método quantitativo, com as características de uma análise retrospectiva, transversal e descritiva.

\subsection{População}

A população é composta pelos pacientes portadores de câncer de próstata atendidos nos departamentos de oncologia, radioterapia e urologia do Hospital Geral Público de Palmas Tocantins (FIGURA 9), referência estadual para este tipo de doença, no período de janeiro a dezembro de 2015.

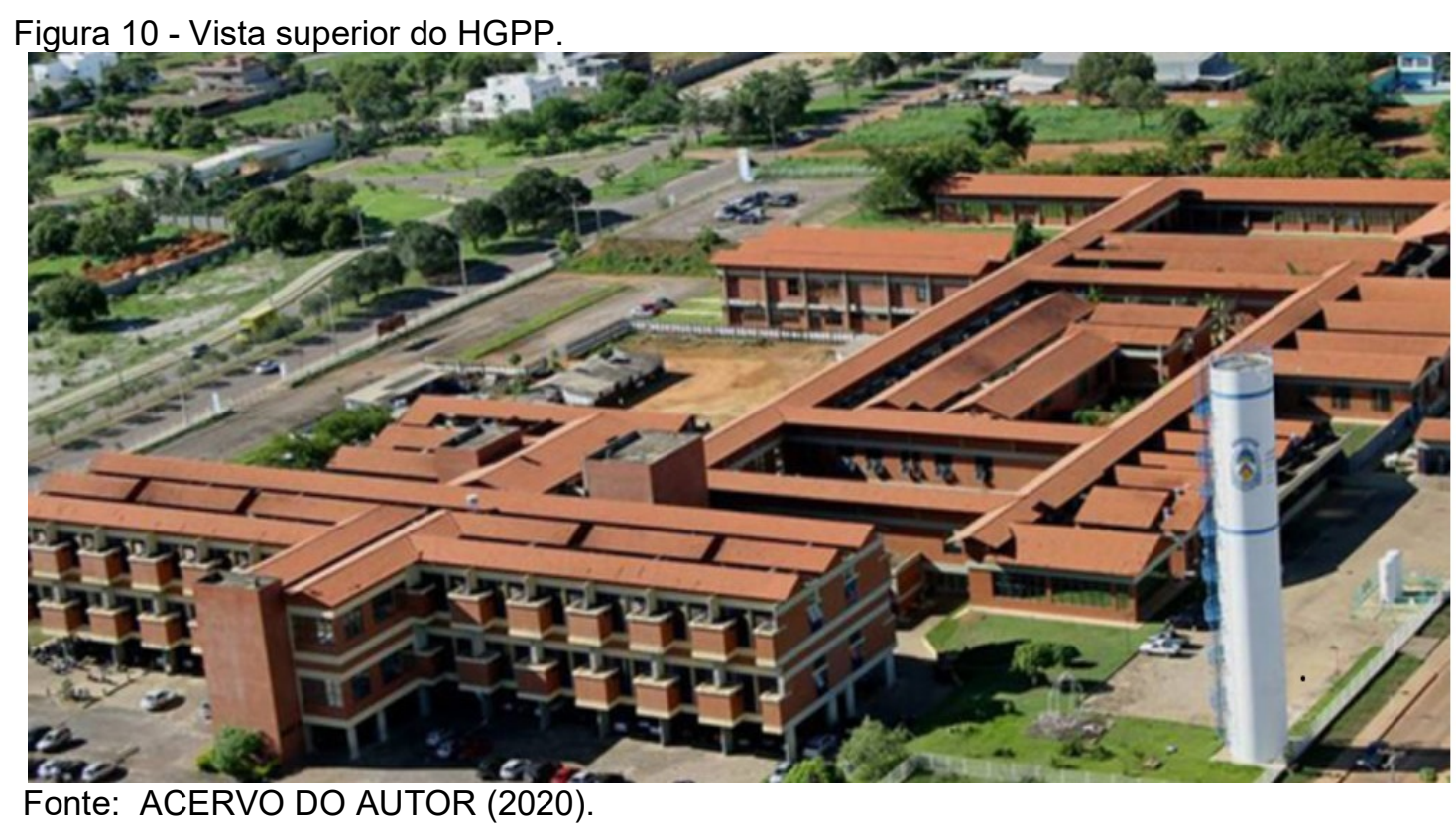

\subsection{Critérios de inclusão}

Adotou-se como requisito de inclusão pacientes com diagnósticos da doença atendidos no HGPP, independente do estágio clínico em que se encontravam, e que disponham de dados clínicos e epidemiológicos adequadamente registrados em seus arquivos. 


\subsection{Período}

Com o levantamento de dados dos pacientes, que obedeceram aos critérios de inclusão, atendidos pelos departamentos de Oncologia, Radioterapia e Urologia do Hospital Geral Público de Palmas - Tocantins, no período de janeiro a dezembro de 2015, através da coleta manual e revisão documental dos prontuários, junto ao Núcleo de Ensino e Pesquisa daquela instituição, identificada através do número 09/2018.

\section{5 Área de estudo}

Trata-se de um estudo retrospectivo a ser realizado na maior unidade de saúde estadual, o Hospital Geral Público de Palmas, popularmente conhecido como HGPP, que, apesar de suas grandes dimensões, convive com os principais problemas do SUS (Sistema Único de Saúde), como superlotação e desabastecimento.

O mesmo representa a instalação de maior complexidade dentro do organograma da secretaria estadual, e para lá convergem a grande maioria dos casos de câncer do Estado e alguns provenientes de Estados vizinhos como sudeste do Pará, leste do Mato Grosso e sul do Maranhão e Piauí.

A unidade presta atendimento de saúde em nível secundário/terciário, sendo os casos de câncer de próstata direcionados aos ambulatórios das subespecialidades (Oncologia, Urologia e Radioterapia), onde são estadiados e encaminhados para o tratamento definido. A Figura 10 mostra o aparelho de radioterapia do HRA. 
Figura 11 - Aparelho de radioterapia do Hospital Regional de Araguaína.

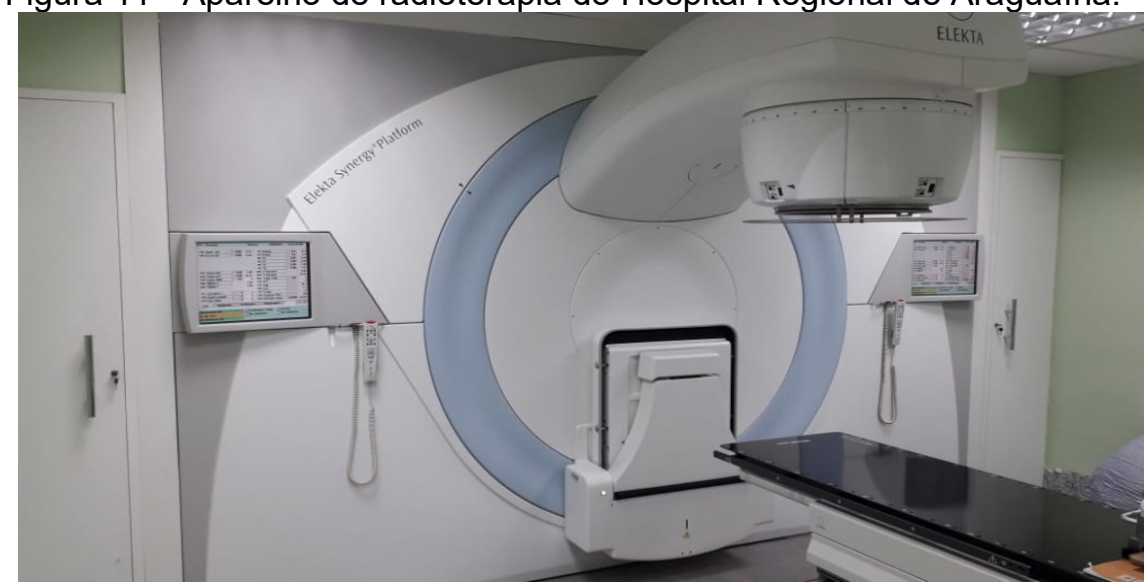

Fonte: ACERVO DO AUTOR (2020).

Os casos em que o tratamento de escolha é a radioterapia são encaminhados ao Hospital Regional de Araguaína (HRA), pois é a única unidade pública estadual que fornece este tratamento (FIGURA 11).

Os que têm indicação de cirurgia radical (prostatectomia), quimioterapia ou bloqueio hormonal são tratados no próprio Hospital Geral Público de Palmas. E, aos que poderiam ser tratados com a Braquiterapia, infelizmente, são encaminhados a outros estados ou conduzidos com uma das outras modalidades terapêuticas, pois ela ainda não é proporcionada pelo estado do Tocantins.

Figura 12 - Serviço de radioterapia do HRA.

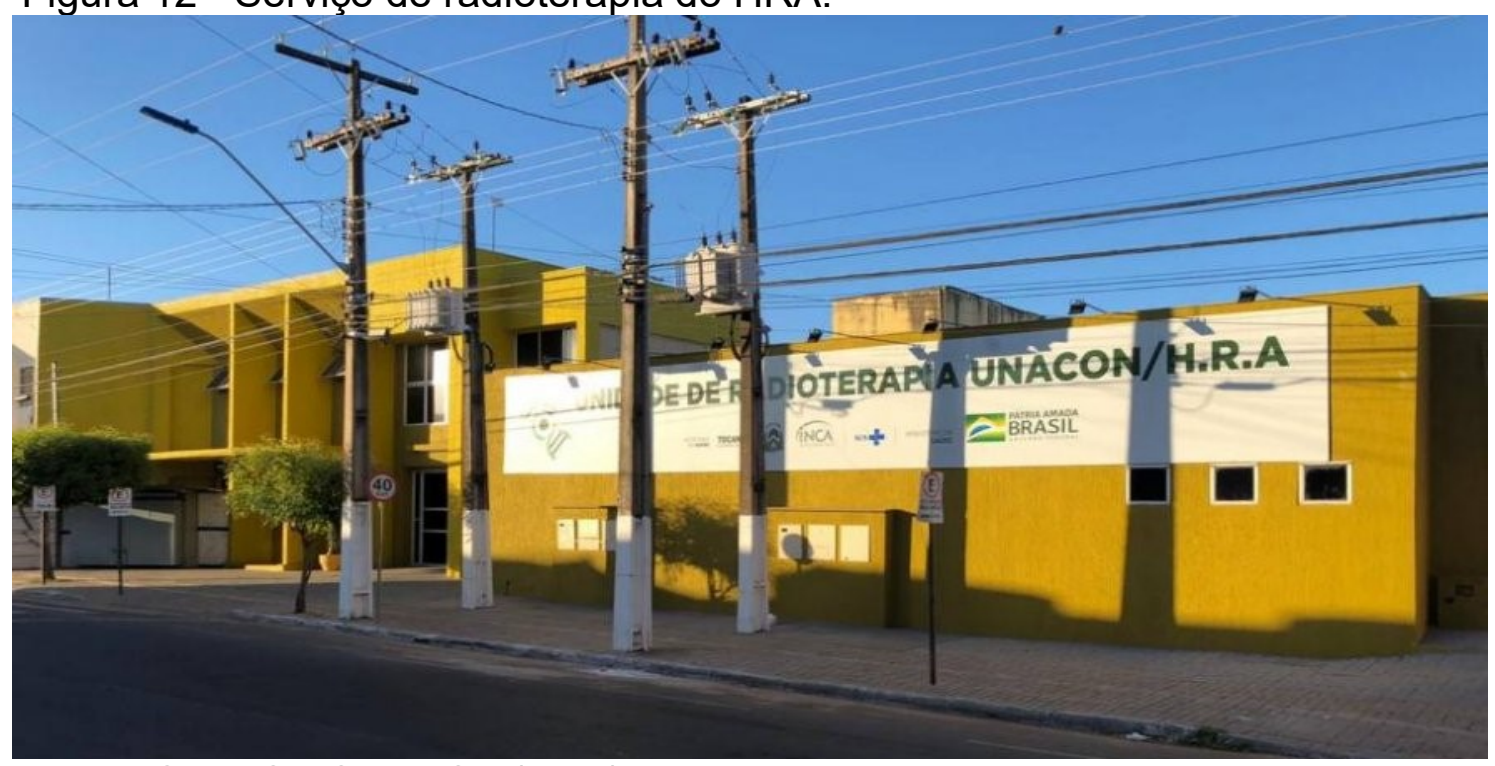

Fonte: ACERVO DO AUTOR (2020). 


\subsection{Procedimentos e análise estatística}

O plano de trabalho foi encaminhado à Secretaria Estadual de Saúde do Tocantins visando a autorização para levantamento dos dados de prontuários junto ao Serviço de Arquivo Médico daquele hospital (SAME).

Em seu aspecto ético, o projeto de estudo foi aprovado pelo Comitê de Ética e Pesquisa (CEP) da FAPAC/ INSTITUTO TOCANTINENSE PRESIDENTE ANTÔNIO CARLOS PORTO NACIONAL LTDA, CAAE: 96173418.5.0000.8075, número do parecer: 2.966 .435 , com o intuito de garantir os interesses dos sujeitos da pesquisa e contribuir no desenvolvimento do estudo dentro de padrões éticos, conforme a Resolução nº 466/12 do Conselho Nacional de Saúde, do dia 12 de dezembro de 2012, a qual regulamenta as pesquisas envolvendo seres humanos para que atendam aos fundamentos éticos e científicos pertinentes (BRASIL, 2012).

Para a coleta dos dados foi elaborado um formulário (APÊNDICE) que foi aplicado pelo pesquisador responsável visando coleta dos dados destes pacientes, suas características pessoais como idade, cor, procedência, do estadiamento clínico e histopatológico da doença, do tempo decorrido entre o diagnóstico e o início do tratamento, qual o tratamento realizado.

Posteriormente, elaborou-se de um banco de informações, sempre resguardando seu sigilo, seguido da análise, organização e tratamento dos dados, método quantitativo, por meio do software estatístico BioEstat $\circledast$, visando a consolidação das informações, produção de resultados e obtenção das respostas aos objetivos deste estudo.

O BioEstat $\circledast$ é um programa voltado aos estudantes de graduação, pós-graduação e pesquisadores na área de biológica que utiliza os mesmos comandos do Microsoft Office. A fonte de dados utilizada no programa é inserida em colunas onde seleciona-se o teste a ser utilizado conforme as variáveis a serem analisadas. O BioEstat $®$ possui mais de 210 testes a serem escolhidos para uso.

Desse modo, os dados quantitativos foram avaliados por meio de duas variáveis: as qualitativas e as quantitativas, onde as variáveis qualitativas serão distribuídas por frequências absolutas e relativas. Já as variáveis quantitativas foram apresentadas por medidas de tendência central de variação com a 
utilização do teste de D’Agostino-Pearson para avaliar a sua normalidade. O teste de D'Agostino-Pearson tem o objetivo de avaliar a normalidade entre os dados, seguindo uma distribuição normal.

A análise de correspondência entre o estadiamento clínico e o tratamento utilizado serão realizados por meio da determinação do Coeficiente de Correlação $(r)$ de Pearson. Para que as variáveis indiquem uma distribuição normal, será fixado o nível alfa com $\mathrm{p}<0,05$ para testar a rejeição da hipótese de nulidade, com amostras aleatórias.

\subsection{Riscos}

Como toda análise envolvendo seres humanos, esta também envolve riscos. A pesquisa obterá dados através de informações colhidas em prontuários, portanto não é previsto risco de natureza física aos participantes. No entanto, é possível que haja eventos indesejados como: Estigmatização pela divulgação de informações quando houver acesso aos dados de identificação; invasão de privacidade; divulgação de dados confidenciais; risco a segurança dos prontuários; resultados serem publicados de maneira inadequada.

Para minimizá-los ratifica-se o compromisso ético desta pesquisa, que irá sempre se basear nas determinações da resolução 466/12 do Conselho Nacional de Saúde, zelando por uma abordagem adequada aos participantes da pesquisa e o cuidado necessário com a base de dados, além de medidas como limitar o acesso aos prontuários apenas pela quantidade e qualidade das informações específicas para a pesquisa, garantir a não violação e a integridade dos documentos, assegurar a confidencialidade e a privacidade, a proteção da imagem e a não estigmatização, garantindo a não utilização das informações em prejuízo das pessoas ou das comunidades.

\subsection{Critérios de paralisação ou encerramento da pesquisa}

Em conformidade com o artigo XI item H da Resolução 466/12, informamos que a pesquisa poderá ser paralisada/encerrada caso se verifique precariedade dos dados que impossibilite a obtenção de uma amostra 
estatisticamente significativa ou a materialização de algum dano aos participantes. Neste caso será feita a comunicação e justificativa fundamentada ao Comitê de Ética e Pesquisa que o avaliou.

\section{RESULTADOS E DISCUSSÃO}

O Gráfico 1 mostra a faixa etária dos pacientes com câncer de próstata que compõem a amostra desta pesquisa, onde observar-se que $45 \%$ dos pacientes analisados correspondiam à faixa de 70 a 79 anos e $33 \%$ pertenciam à faixa de 60 a 69 anos.

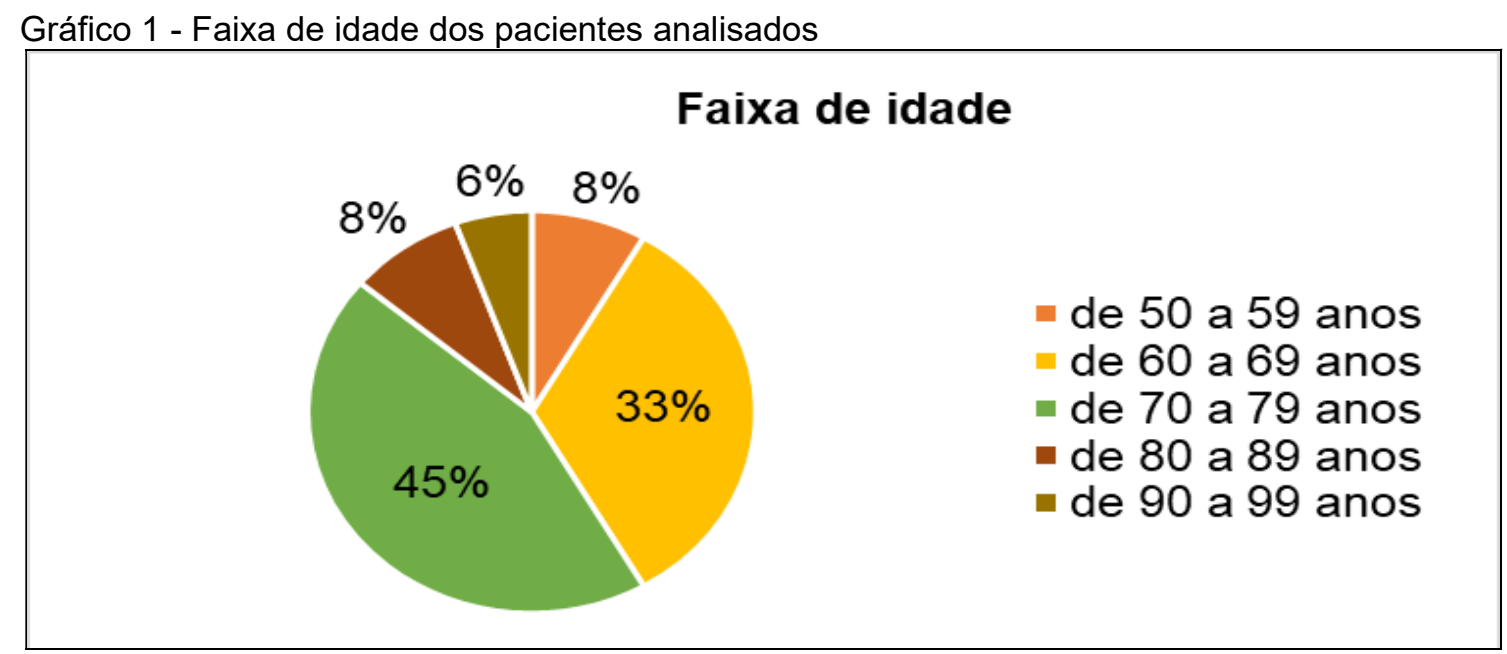

Fonte: Núcleo de Ensino e Pesquisa do HGPP

O relatório do Instituto Nacional do Câncer (INCA, 2020) indica a estimativa para o triênio 2020 a 2022 de 65.840 novos casos de câncer de próstata a cada ano.

Sousa et al. (2018) destacam que o câncer de próstata é o segundo câncer que mais mata no Brasil. Mais do que qualquer outro tipo, é considerado um câncer da terceira idade, já que cerca de $75 \%$ dos casos no mundo ocorrem a partir dos 65 anos (INCA, 2020).

A idade é um fator preocupante de risco para o câncer de próstata, já que $62 \%$ dos casos diagnosticados ocorrem em homens com 65 anos ou mais e o risco de adoecer é potencializado com a idade (DAMIÃO et al., 2015). Nesse 
estudo, percebeu-se a prevalência de homens diagnosticados com câncer de próstata entre os 70 a 79 anos de idade.

Com relação à procedência, local de moradia dos paciente, percebe-se que houve uma predominância de indivíduos provenientes da cidade de Palmas, estado do Tocantins, no entanto, também observa-se indivíduos provenientes de outros estados, como Pará, que faz divisa ao norte (GRÁFICO 2).

Gráfico 2 - Local de origem e número de pacientes analisados

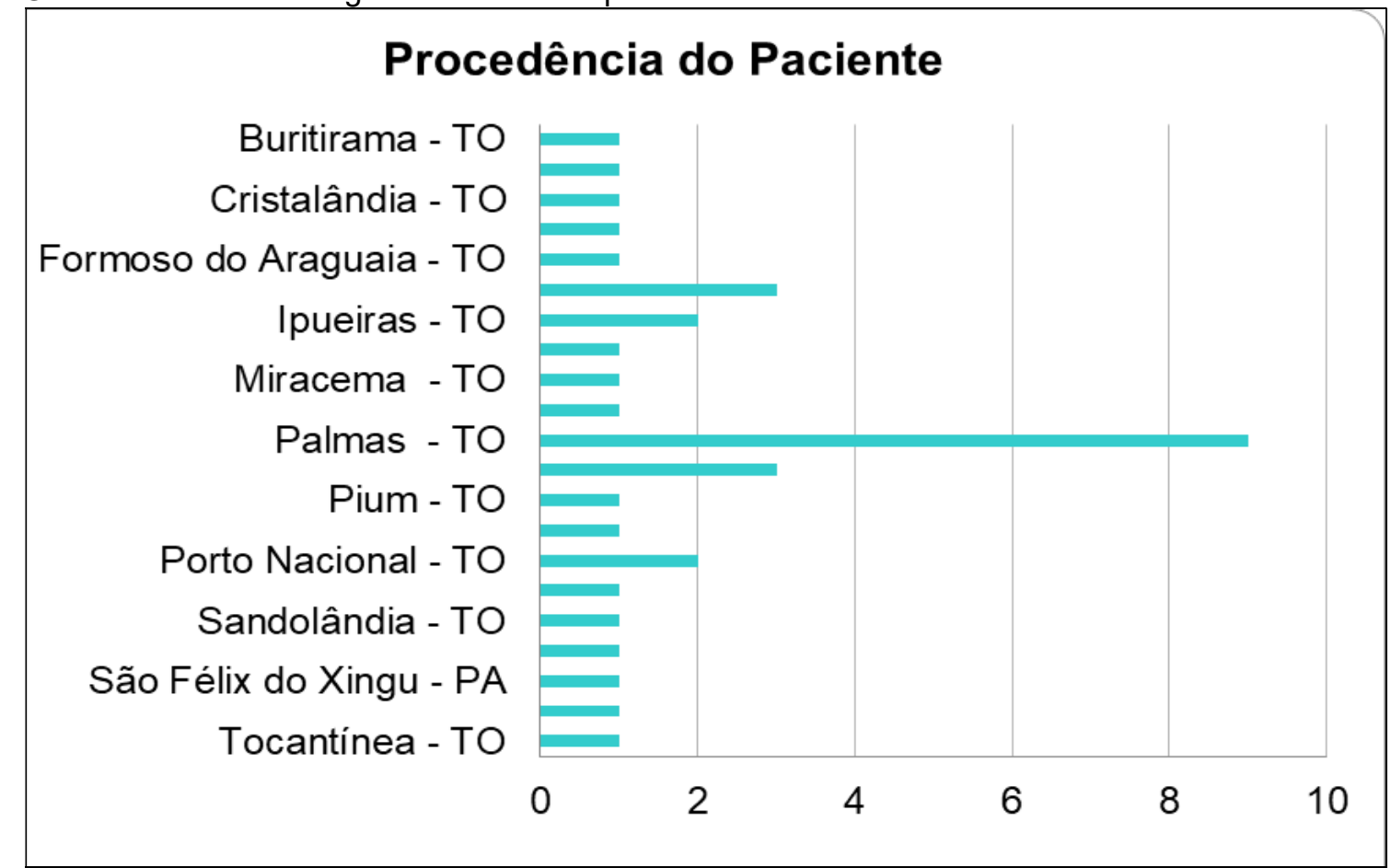

Fonte: Núcleo de Ensino e Pesquisa do HGPP.

Bós e Bós (2004) comentam que a escolha em buscar atendimento médico diante de uma alteração na saúde depende muito da situação econômica, social, demográfica e epidemiológica. Podendo influenciar inclusive na escolha da instituição, se pública ou privada. Além disso, os fatores culturais, econômicos e políticos sofrem mudanças constantemente, por isso a importância em monitorar tais aspectos para propor medidas públicas eficazes no combate ao $\mathrm{CaP}$.

A Sociedade Brasileira de Urologia recomenda que o teste de antígeno-específico, conhecido como PSA, para o câncer de próstata seja realizado anualmente, associado ao exame clínico, por via retal, para os homens que se encontram na faixa etária entre 50 e 80 anos de idade. Nos homens que 
têm familiares com diagnóstico positivo de câncer de próstata, a realização dos testes deve começar aos 40 anos de idade (CHOW et al., 2018).

O Gráfico 3 apresenta o tempo entre o diagnóstico e o início do tratamento. Nota-se que houve predominância entre o diagnóstico e o tratamento do câncer de próstata de 1 a 6 meses, tempo considerado como bom ou razoável, no entanto, para $27,77 \%$ este tempo variou entre 1 a 3 anos, o que é considerado bastante longo e inadequado, pois possibilita a progressão da doença e comprometimento do resultado terapêutico, como observa Castro et al. (2011).

Gráfico 3 - Tempo entre o diagnóstico e o início do tratamento dos pacientes analisados

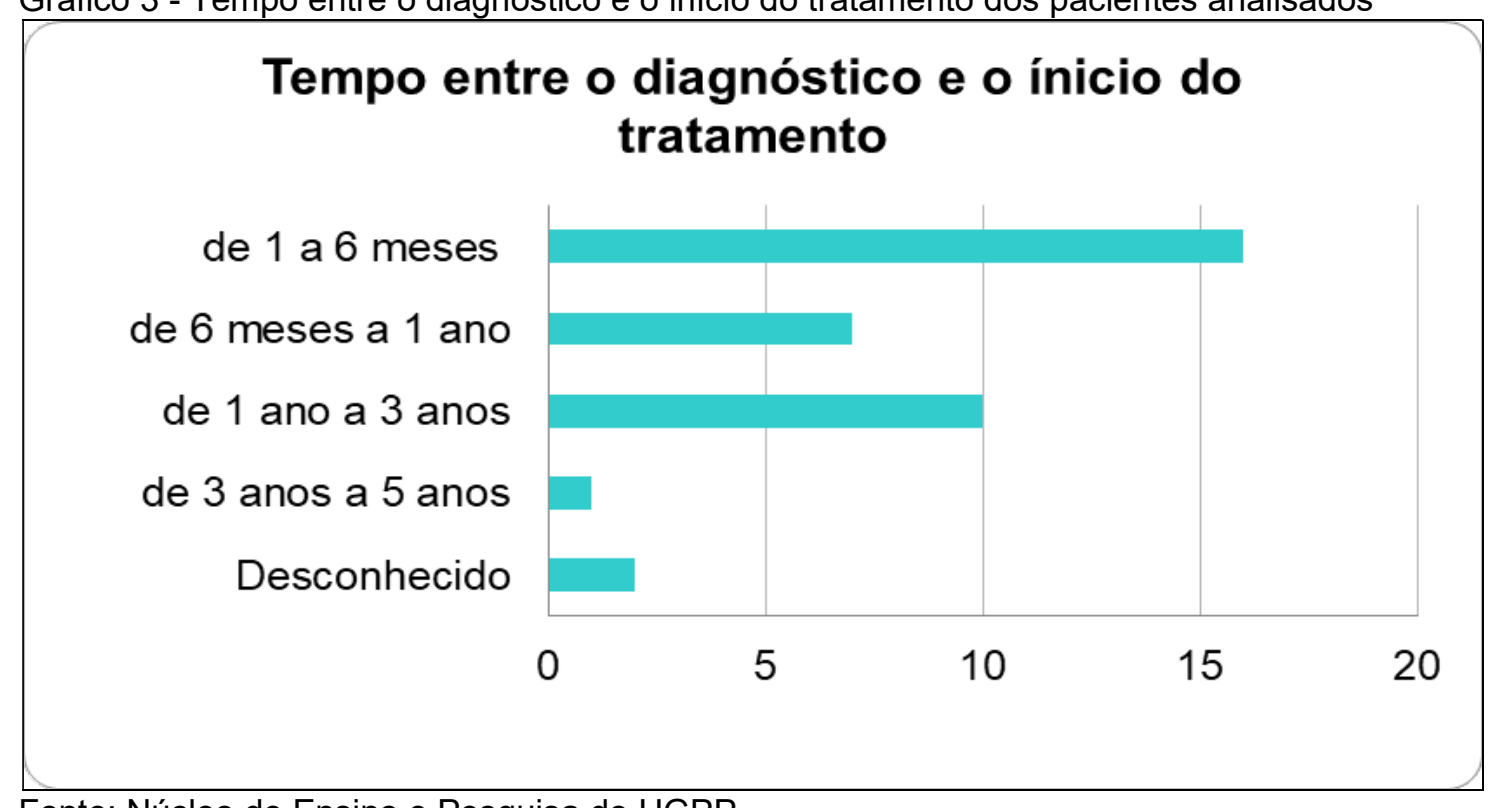

Fonte: Núcleo de Ensino e Pesquisa do HGPP.

O câncer é uma doença agressiva, com altas taxas de mortalidade. Assim, a importância em se detectar a alteração celular desde o início, de forma precoce, para que o tratamento seja eficaz, fato que mostra a necessidade de políticas de rastreamento mais eficazes (INCA, 2018).

Segundo o Portal de Urologia (2018, p. 1) o rastreamento universal de toda população masculina (desconsiderando idade e história familiar) apresenta diferentes aspectos, já que pode diagnosticar, "entre outros, câncer de próstata de baixa agressividade, que não necessita de tratamento, cujos pacientes são submetidos a biópsias, que têm potencial de complicações (infecção local), e, eventualmente, tratamentos radicais com potencial impacto na qualidade de vida". 
Por isso, para determinação do tratamento mais adequado, diversos fatores devem ser observados, tais como o escore de Gleason, o estadiamento, a idade, a presença de comorbidades e os possíveis efeitos colaterais do tratamento.

O Gráfico 4 apresenta os dados obtidos com relação à escala de Gleason.

Gráfico 4 - Escala de Gleason dos pacientes

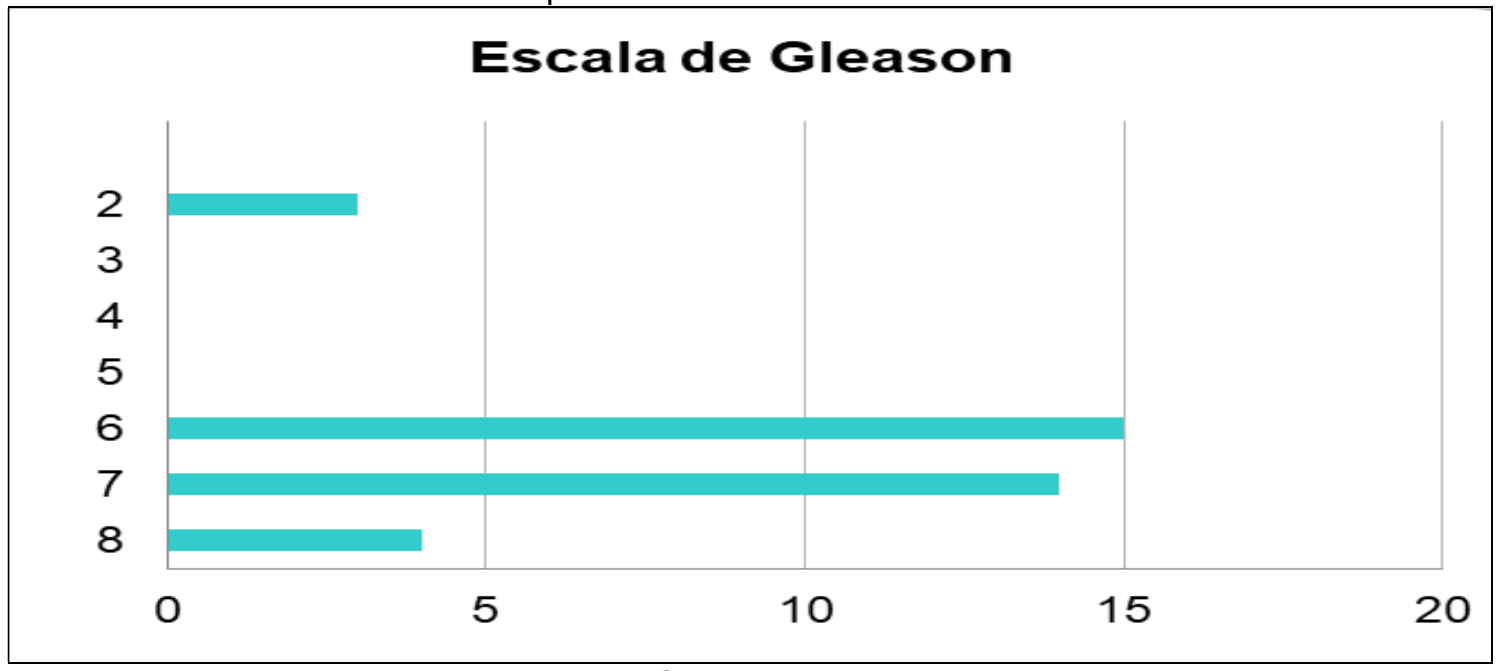

Fonte: Núcleo de Ensino e Pesquisa do HGPP

Os dados referentes à escala de Gleason são fundamentais, pois o grau histológico representa, em cada caso avaliado, uma característica morfológica que pode estimar os casos de comportamento biológico mais agressivo do câncer (SCHMIDT, 2018).

Assim, o escore de Gleason (TABELA 1) destaca-se como um importante parâmetro patológico para a estratificação de risco e a tomada de decisão terapêutica em pacientes com câncer de próstata (HELPAP et al., 2015). 
Tabela 1 - Escore de Gleason e evolução esperada

ESCORE DE GLEASON

menor ou igual a 6

7

8

9 ou 10

\section{CARACTERÍSTICAS DO TUMOR}

Crescimento lento (pouco agressivo)

Crescimento intermediário (moderadamente agressivo)

Crescimento rápido (agressivo)

Crescimento muito rápido (muito agressivo)

Fonte: International Society of Urological Pathology (2020).

O escore de Gleason é uma pontuação dada a um câncer de próstata baseada em sua aparência microscópica, pode variar de 2 a 10. Um escore 2 aponta um melhor prognóstico, enquanto o escore 10 indica um pior. $\mathrm{O}$ escore final é uma combinação de dois escores diferentes, que variam cada um de 1 a 5 . A Figura 12 mostra a escala de Gleason com a indicação das amostras histológicas.

Figura 13 - Escala de Gleason para a classificação histológica do adenocarcinoma da próstata.

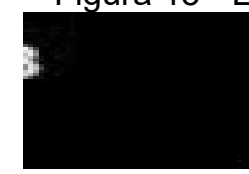

Gleason varia diferenciado)

\footnotetext{
e do colo vesical por
}

nais espessa, uma

expulsar a urina e

ie com pequenas

equentes. Com o

ir da bexiga, ela

Fonte: NEWSLETTER TDT (2015).

De acordo com o escore de Gleason:

Grau 1 - A próstata cancerosa se parece muito com o tecido normal. As glândulas são pequenas, bem-formadas e muito próximas.

Grau 2 - O tecido ainda possui glândulas bem formadas, mas elas são maiores e possuem mais tecido entre cada uma. 
Grau 3 - O tecido ainda possui glândulas reconhecíveis, mas as células são mais escuras. Em uma magnificação maior, algumas destas células deixaram as glândulas e estão começando a invadir o tecido circundante.

Grau 4 - O tecido possui poucas glândulas reconhecíveis. Muitas células estão invadindo o tecido circundante.

Grau 5 - O tecido não possui glândulas reconhecíveis.

Os tumores com escore de Gleason de 2 a 6 são considerados com um bom prognóstico. Nesta pesquisa, houve uma predominância de pacientes com Gleason 6 (41,66\%), indicando tumores de evolução (crescimento) lento, o Gleason 7 esteve presente em $38,88 \%$ da amostra. Quando se considera apenas o Gleason 7 e 8 verifica-se que eles estão presentes em metade da população.

Löbler et al. (2012) destaca que a graduação de Gleason observa o padrão arquitetural do $\mathrm{CaP}$, onde 1 é bem diferenciado e 5 é pobremente diferenciado.

Habitualmente a escala de Gleason é associada ao estadiamento da doença para observar o tratamento indicado de forma a não comprometer a qualidade de vida do paciente e atingir de modo eficaz o tumor.

O tratamento do câncer de próstata abrange desde a vigilância ativa até o tratamento com bloqueio hormonal, radioterapia e cirurgia, prostatectomia. Por isso, a importância de relacionar diversos fatores, como escore de Gleason, estadiamento, idade, efeitos colaterais ou a presença de outras comorbidades (VIANA, 2017).

Determinou-se que escores de Gleason com valores de 8 a 10 apresentam maior possibilidade de recorrência após o tratamento primário, assim como maior letalidade quando comparados aos valores de 2 a 6 . No entanto, o nível 7 é bastante heterogêneo, pois quando é ocasionado pela soma de $4+3$ é classificado como crescimento rápido (agressivo), no entanto, $3+4$ pertence ao nível de agressividade intermediário, mais baixo de recorrência (LÖBLER et al., 2012).

Para os pacientes que apresentam baixo risco de agressividade e de recorrência e que não são propensos à vigilância ativa, além daqueles com risco intermediário, a opção indicada de tratamento é a prostatectomia radical ou a 
radioterapia, cujas taxas de cura são de $95 \%$ e $75 \%$ respectivamente, em 10 anos (FAY et al. 2019).

Os pacientes considerados com risco elevado de recorrência devem passar por um tratamento mais agressivo devido ao potencial metastático da doença e assim realiza-se a prostatectomia radical, que reduz de modo eficaz 0 tumor e os níveis séricos do PSA.

O Gráfico 5 mostra que os pacientes analisados apresentaram o estadiamento II em $41,66 \%$ dos casos, o que significa doença em estágio localizado e passível de tratamento curativo, este é o cenário ideal para a abordagem do paciente. A estatística americana é de aproximadamente $90 \%$ dos pacientes diagnosticados em fase inicial, localizada da doença, mas neste estudo se somarmos os pacientes com doença avançada, os estadios III e IV, verificamos que representam a maioria da indivíduos, 52,76\%. Este dado é importante marcador de mau prognóstico, pois significa impossibilidade de cura para estes pacientes e todo o tratamento a eles aplicados irá visar apenas cuidades paliativos. Esta informação traz também reflexão importante quanto a eficiência das campanhas realizadas no estado para detecção precoce do câncer de próstata.

Gráfico 5 - Grau de estadiamento da amostra desta pesquisa

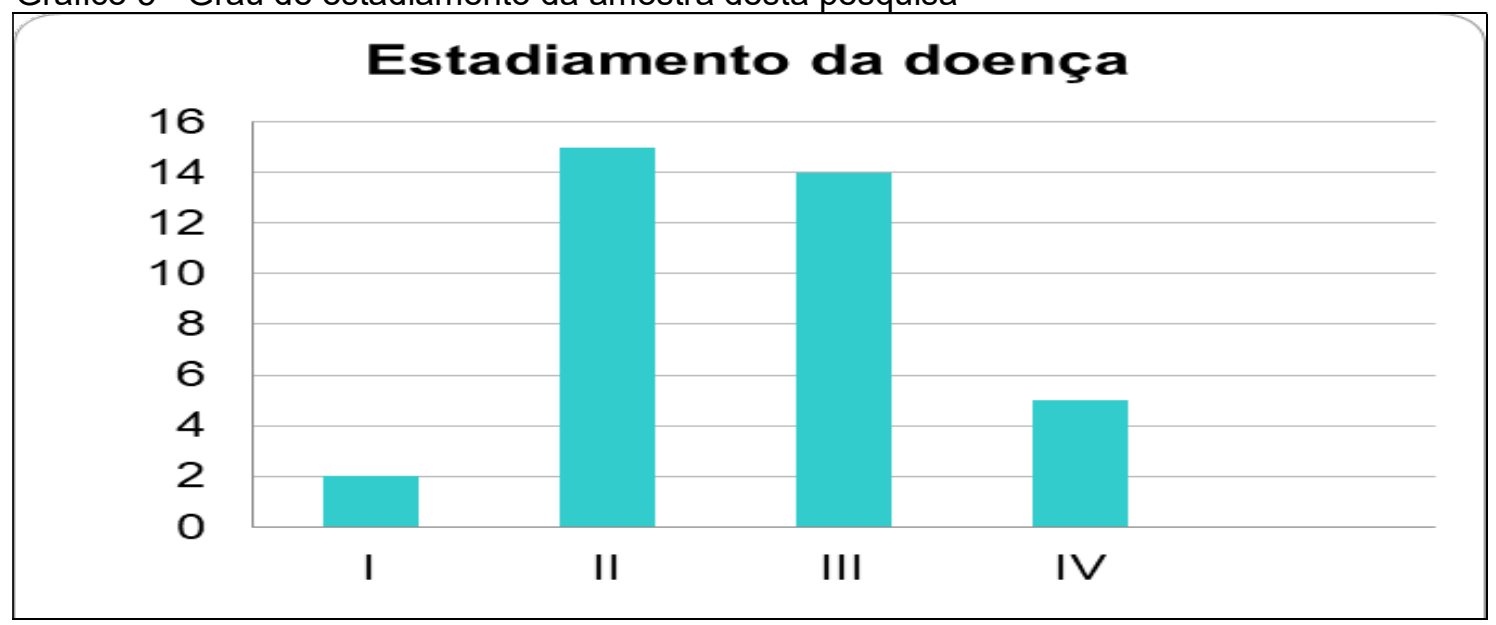

Fonte: Núcleo de Ensino e Pesquisa do HGPP

A primeira análise do estadiamento clínico do CaP ocorre através do toque retal e dosagem do PSA. Em situações específicas, a realização de uma radiografia de tórax, cintilografia óssea, tomografia computadorizada ou 
ressonância magnética de pelve e abdome podem ser necessárias para a melhor avaliação de possíveis metástases (FILHO; DAMIÃO, 2010).

Com relação ao tratamento utilizado, verificou-se diferentes abordagens terapêuticas, uma vez que a amostra apresentava-se em vários estadios diferentes da doença. Nota-se no Gráfico 6 que o tratamento de bloqueio hormonal isolado $(\mathrm{BH})$ foi o mais utilizado com $39 \%$, depois a associação de $\mathrm{BH}$ e radioterapia com 28\%, e em terceiro a associação entre $\mathrm{BH}$, cirurgia (prostatectomia) e radioterapia com 19\% do total de pacientes pesquisados.

Este dado vai ao encontro do que foi verificado quanto ao estadiamento clínico. Observamos que a maioria dos pacientes possuía estadiamento avançado no momento do diagnóstico, então naturalmente o tipo de tratamento mais aplicado foram terapias sem finalidade curativa, neste caso a terapia hormonal isolada. Vale lembrar que ela pode ofertar possibilidade de cura quando é adjuvante a outros métodos, cirurgia ou radioterapia.

Gráfico 6 - Tipos de tratamentos realizados

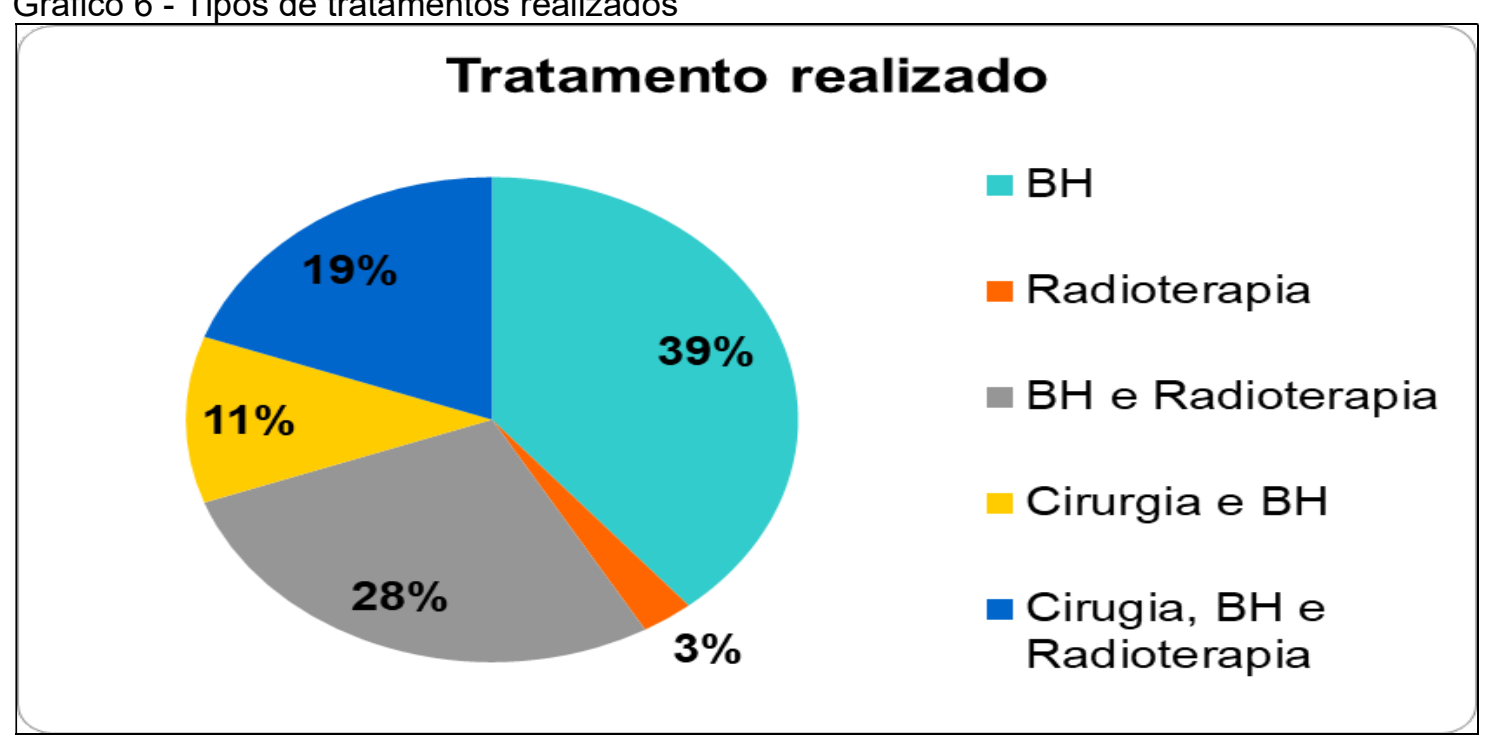

Fonte: Núcleo de Ensino e Pesquisa do HGPP

O tratamento visa prevenir a morte do indivíduo e a incapacidade proveniente do $\mathrm{CaP}$, reduzindo as complicações relacionadas à intervenções (SCHMIDT, 2018).

Pacientes considerados com $\mathrm{CaP}$ de baixo ou intermediário risco apresentam baixo PSA, Gleason menor ou igual a 7 e a doença localizada na 
próstata. Aqueles pacientes que tenham expectativa de vida superior a cinco anos e sem contraindicação cirúrgica a recomendação é a prostatectomia radical. Conforme o risco, pode-se também realizar, juntamente, a linfadenectomia pélvica. Nessa cirurgia, são retiradas por inteiro a próstata e as vesículas seminais. Os principais efeitos colaterais da prostatectomia radical são a disfunção erétil e a incontinência urinária, o avanço da idade pode potencializar as complicações pós-cirúrgicas (GACCl et al., 2008; FILHO; DAMIÃO, 2010).

Além disso, pode-se também realizar a radioterapia para $\mathrm{CaP}$ de baixo risco, a hormonioterapia e a vigilância ativa. Uma das possíveis sequelas da radioterapia são as lesões actínicas (processo inflamatório pós radiação) de órgãos pélvicos como bexiga e reto, que podem aparecer ao longo dos anos de tratamento (FILHO; DAMIÃO, 2010; OLIVEIRA, 2015).

A vigilância ativa é uma prática bastante seletiva que é indicada quando o paciente não deseja nenhum dos outros tratamentos devido à possíveis complicações. É realizada através de exames e consultas periódicas, geralmente a cada seis meses. Essa classificação é baseada no toque retal, PSA, métodos de imagem como a ressonância multiparamétrica e principalmente na biópsia da próstata (PORTAL DA UROLOGIA, 2017). A Figura 13 apresenta a classificação Tumor Nodo metástase para CaP.

Câncer de próstata com potencial metastático elevado devem ser tratados de forma mais agressiva. Assim, são utilizados diferentes métodos associados como a radioterapia, bloqueio hormonal e a prostatectomia. O momento da sua introdução, duração do tratamento e o tipo de bloqueio empregado pode variar conforme o caso em questão (BRETAS et al., 2012).

Com relação ao local de tratamento observou-se que o Hospital Geral Público de Palmas realizou a maioria dos tratamentos, 52,77\%(GRÁFICO 7). Isso justifica-se pelo fato que a maior parte dos pacientes residiam em Palmas, facilitando assim o deslocamento para o tratamento. Todavia, também verificou-se um número considerável de tratamentos nas cidade de Araguaína no Tocantins, com $25 \%$ dos casos e Imperatriz, no estado no Maranhão, com $16,66 \%$ dos pacientes. A análise da pesquisa mostrou que $44,43 \%$ do HGPP foram encaminhados para outras cidades, sendo que em 19,43\% elas ficavam em outros estados, Distrito Federal e Maranhão, demonstrando a grande incapacidade daquela unidade para tratamento de sua demanda, grande 
dependência de referenciamento para outras unidades, elevando os custos do tratamento com gastos para terapia fora de domicílio e implicando em aumento do tempo de espera pela terapia.

Figura 14 - A classificação Tumor Nodo Metástase (TNM) para câncer de próstata

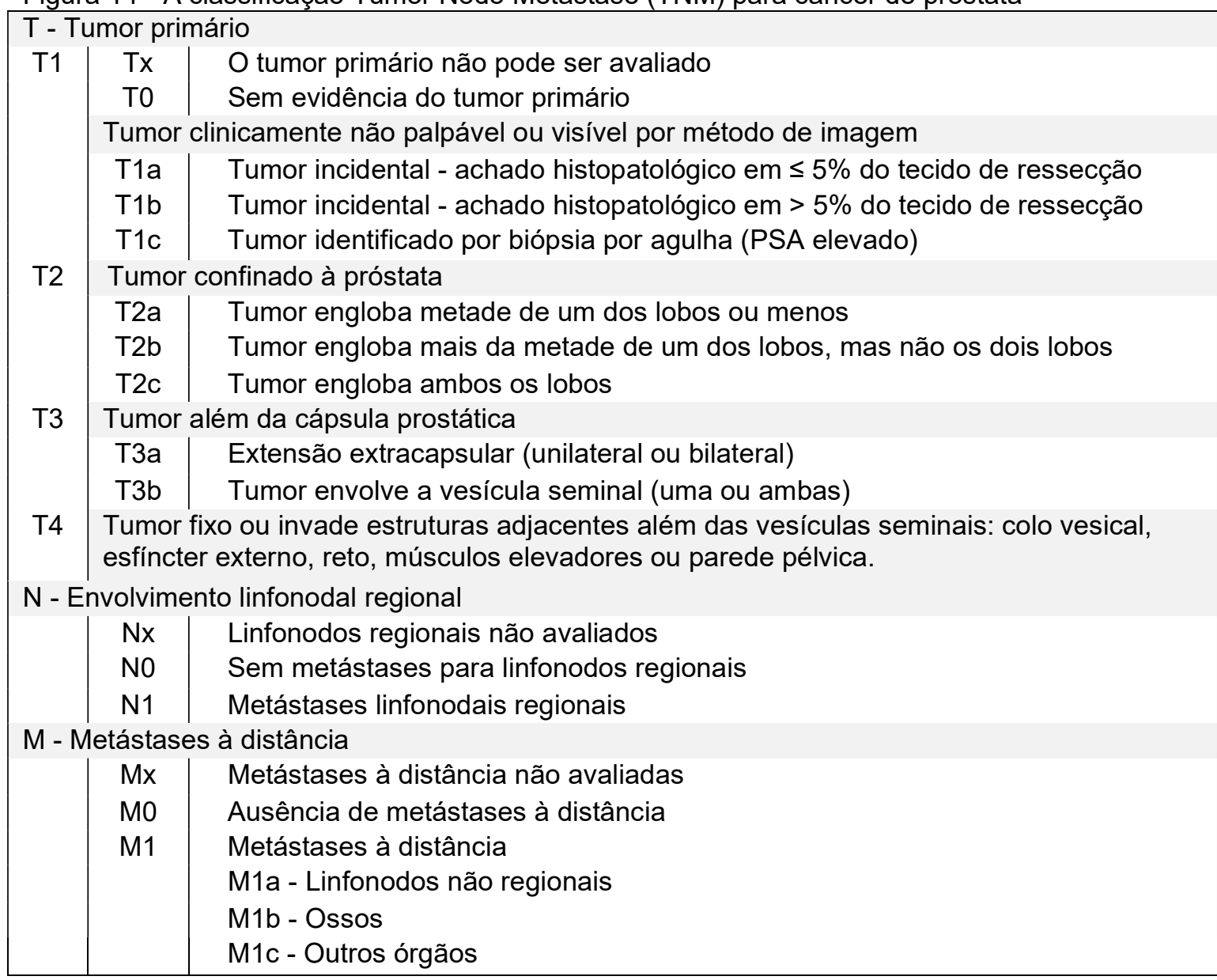

Fonte: SOBIN (2002); MADEIRA (2017).

Observou-se que os tratamentos foram realizados em hospitais na cidade de Brasília, Palmas (Hospital Geral de Palmas e hospital particular), Araguaína (Hospital Regional de Araguaína) e Imperatriz, no estado do Maranhão. 
Gráfico 7 - Local de tratamento dos pacientes analisados

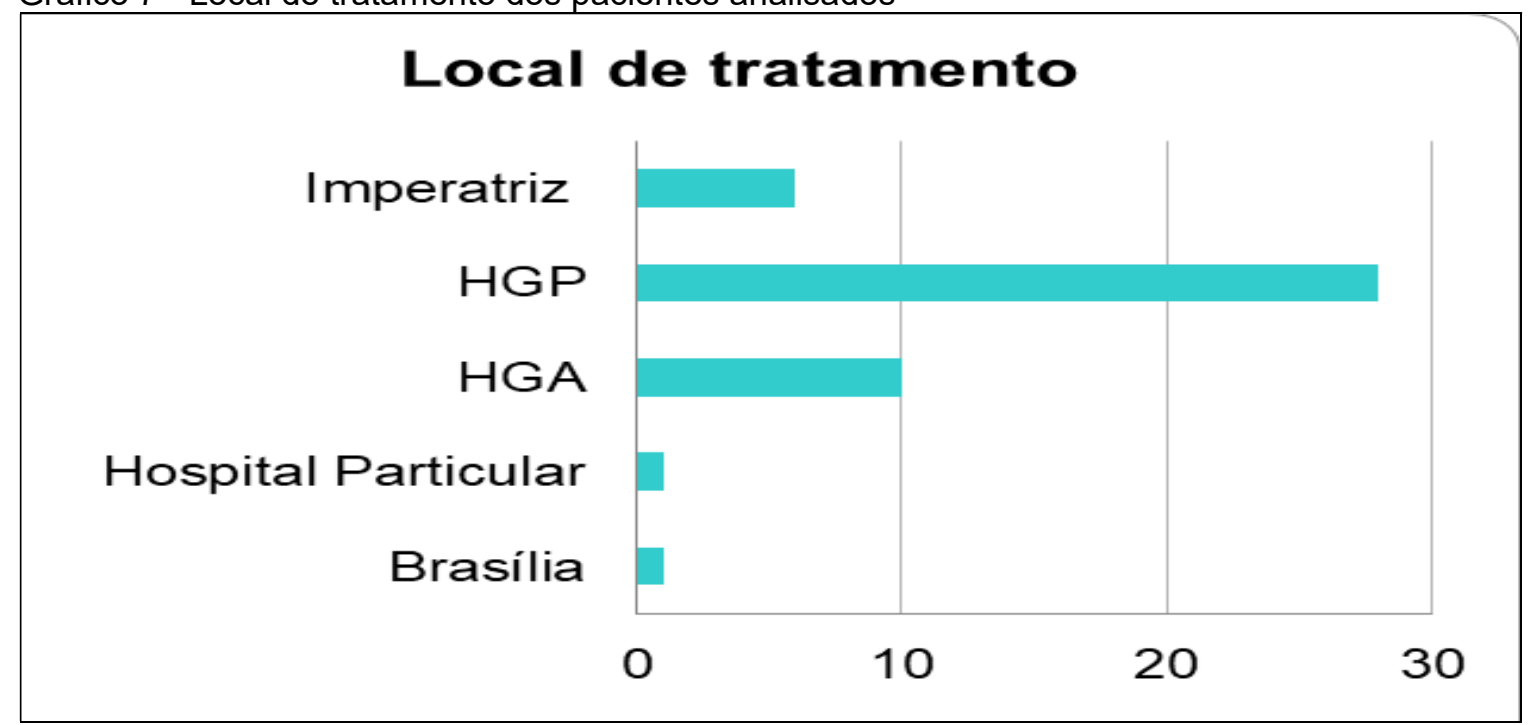

Fonte: Núcleo de Ensino e Pesquisa do HGPP

A última análise realizada refere-se à aptidão para o tratamento por braquiterapia e verificou-se que uma parcela significante de $36,11 \%$ dos analisados estavam aptos à braquiterapia, os demais apresentavam elevado grau de estadiamento da doença, o que impossibilita esta opção GRÁFICO 8). Estes pacientes aptos foram tratados através de outros métodos, parte deles encaminhadas a outros locais e foram expostos a mais dificuldades para conclusão do seu tratamento, além de sujeitos a mais efeitos indesejáveis. Para a secretaria estadual foi gerado demanda significativa de encaminhamentos e custos para atender estes pacientes.

A braquiterapia só é indicada para tumores confinados a glândula (Estadiamento I ou II / TABELA 2), com PSA baixo (geralmente menor do que 10 $\mathrm{ng} / \mathrm{mL}$ ) e pouco agressivos (com Gleason 6 e, ocasionalmente, 7), principalmente para aqueles que não desejam realizar um tratamento longo de radioterapia externa ou retirar a próstata, prostatectomia radical (INSTITUTO VENCER O CÂNCER, 2018). 
Gráfico 8 - Aptidão dos pacientes à Braquiterapia

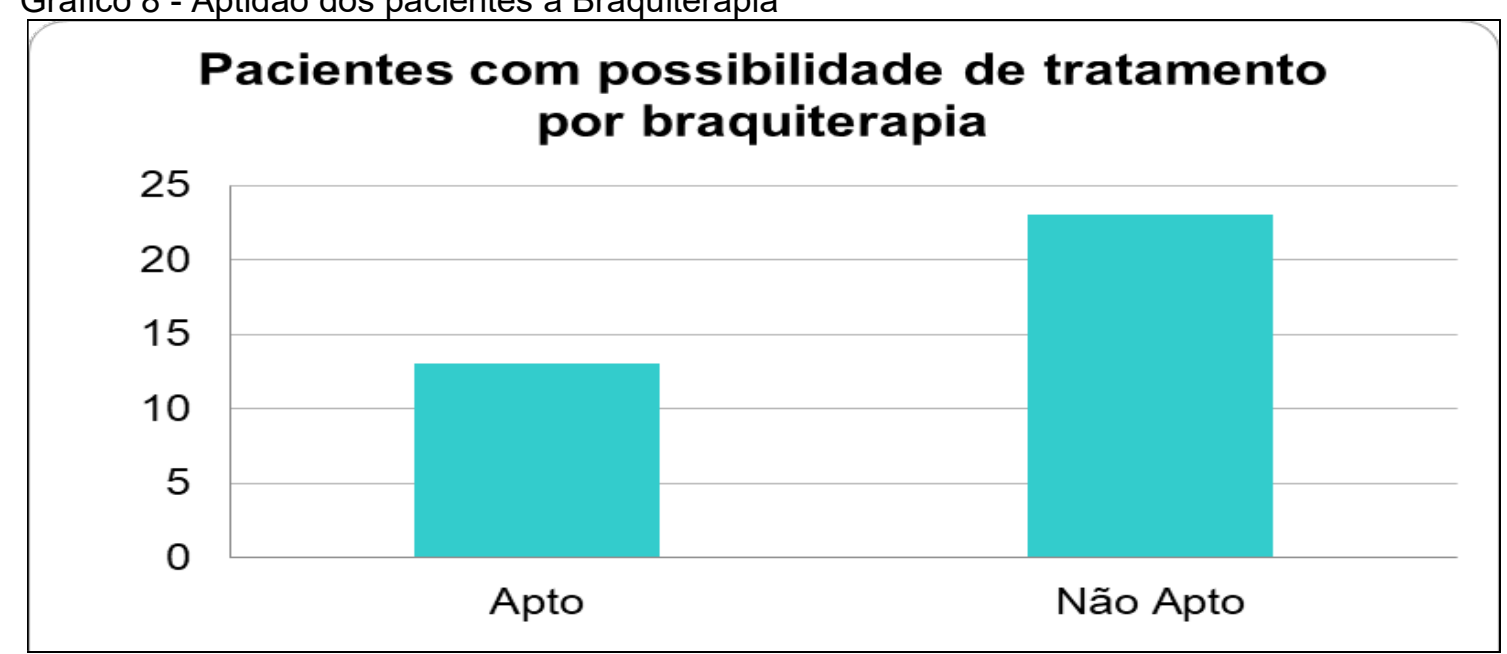

Fonte: Núcleo de Ensino e Pesquisa do HGPP

A braquiterapia consiste em uma forma de tratamento que envolve a colocação de fontes radioativas seladas junto ao tumor, por isso, uma forma de radioterapia interna. Os materiais, também chamados de sementes radioativas de lodo-125, determinam a liberação de altas doses de radiação apenas nas proximidades da área de implantação, sem que um grande número de células normais seja atingido (HOSPITAL ISRAELITA ALBERT EINSTEIN, 2016; SOUZA, 2018).

Tabela 2 - Estadiamento do câncer de próstata

\begin{tabular}{|c|c|}
\hline ESTÁDIO & DESCRIÇÃO \\
\hline Estádio I & Câncer encontrado ao acaso ou devido ao aumento do PSA. \\
\hline Estádio II & $\begin{array}{c}\text { Câncer encontrado devido à presença de um nódulo } \\
\text { na próstata, localizado em um só lado (IIA) ou em ambos os lados (IIB), } \\
\text { porém confinado à próstata. }\end{array}$ \\
\hline Estádio III & $\begin{array}{c}\text { Câncer que infiltrou os tecidos ao redor da próstata, como vesícula seminal } \\
\text { (IIA), reto (IIIB) e bexiga (IIIC). }\end{array}$ \\
\hline Estádio IV & $\begin{array}{c}\text { Câncer que se espalhou para os linfonodos (IVA), } \\
\text { ossos ou outros órgãos (IVB). }\end{array}$ \\
\hline
\end{tabular}

Fonte: INSTITUTO VENCER O CÂNCER (2018). 
A braquiterapia apresenta uma elevada eficiência e relativa conveniência, já que o paciente é submetido a um único procedimento. Este tem duração de duas a três horas, onde o paciente passa a noite internado e tem alta no dia posterior. O procedimento causa, normalmente, pouco desconforto e dor após a implantação das sementes de iodo (MORI, 2016; INSTITUTO VENCER O CÂNCER, 2018; CARLECH, 2019).

Isto representa um ponto relevante e sensível no tocante à saúde pública do estado. O Hospital Geral de Palmas possui apenas cerca de 8 leitos disponíveis para todas as patologias urológicas de emergência, eletivas, benignas e oncológicas, o que provoca uma longa espera por vagas para o tratamento cirúrgico desta patologia, e que quando ocupados demoram em média 4 dias para estarem novamente disponíveis. Considerando a amostra deste estudo, isso significaria 52 dias/leito a mais para o hospital ao ano. Percebe-se a grande contribuição do método braquiterápico, pois poderia contribuir para atender à demanda de pacientes com doença localizada e de risco baixo a intermediário, sem a necessidade de ocupação desses leitos.

Outro benefício importante deste método é a menor possibilidade de efeitos colaterais, como a disfunção erétil (15 a 25\%) e incontinência urinária (9\%), enquanto que na cirurgia a impotência sexual chega a $70 \%$ dos casos. Destaca-se também o retorno precoce às suas atividades, o que ocorre em apenas dois dias, ao passo que na cirurgia são necessários em média 4 dias de internamento hospitalar e 30 dias de afastamento. Na radioterapia externa são realizadas curtas sessões, porém que duram em média 4 a 6 semanas (ONCOGUIA, 2015; CARLECH, 2019).

O custeio dos tratamentos pela rede pública é feito pelo Sistema de Gerenciamento da Tabela de Procedimentos Médicos (SIGTAP) e OPM do SUS, sistema único de saúde. Criado em janeiro de 2008, O SIGTAP é um dos fundamentais recursos para a manutenção da saúde financeira dos serviços de saúde que prestam atendimento ao Sistema Único de Saúde, sendo este um instrumento para fortalecer o processo de tomada de decisões no âmbito financeiro. Na Tabela 3 estão destacados os valores correspondentes aos tipos de tratamentos para o câncer de próstata, baseados na tabela SIGTAP. 
Tabela 3 - Características dos tratamentos para câncer de próstata.

\begin{tabular}{|cccc|}
\hline Tipo de tratamento & Complexidade & $\begin{array}{c}\text { Duração do } \\
\text { tratamento }\end{array}$ & Valor (em reais) \\
\hline Braquiterapia & Alta & 30 min -2 horas & $\mathrm{R} \$ 5.838,00$ \\
$\begin{array}{c}\text { Radioterapia externa } \\
\begin{array}{c}\text { Prostatectomia } \\
\text { radical }\end{array}\end{array}$ & Alta & 4 a 6 semanas & $\mathrm{R} \$ 5.838,00$ \\
\hline \begin{tabular}{c} 
Fonte: SIGTAP (2020). \\
\hline
\end{tabular} & Alta & 4 dias & $\mathrm{R} \$ 4.416,26$ \\
\hline
\end{tabular}

Inicialmente nota-se que o tratamento braquiterápico, juntamente com a radioterapia convencional, tem um custo mais elevado, aproximadamente $25 \%$ maior. Porém, vale destacar pontos importantes para a gestão de recursos. Como já abordado anteriormente, por dispensar a necessidade de leitos, permitiria diminuir a necessidade de internamentos e em relação à radioterapia externa, evitaria o encaminhamento de vários pacientes para a cidade de Araguaína, distante 400 quilômetros de Palmas e único local onde se tem instalado equipamento público para radioterapia no estado. Destaca-se que neste estudo houve pacientes que realizaram o tratamento em outros estados, devido ao aparelho estar com problemas técnicos, fato recorrente nos últimos anos.

Ressalta-se ainda que o tratamento com radioterapia também gera elevado gasto público para financiamento do tratamento fora de domicílio (TFD), garantido às famílias para custeio de gastos durante a terapia (6 a 8 semanas). Por fim, é importante destacar o impacto financeiro de menor proporção da braquiterapia aos pacientes por possibilitar um retorno precoce às atividades corriqueiras, que em média ocorre com dois dias (JUNIOR, 2017).

De acordo com Marques (2019) o custo associado aos profissionais pode ser reduzido com o aumento de experiência da equipe na realização de todas as etapas da braquiterapia. Assim, o aumento da experiência técnica dos profissionais, geralmente, resulta em um maior aumento da eficiência e eficácia 
na utilização da técnica e minimiza o tempo durante todo o processo de sua execução, desde a inserção do material até o tratamento.

\section{CONCLUSÃO}

No presente trabalho foi examinada a população de pacientes portadores de câncer de próstata atendidos no Hospital Geral Público de Palmas, no ano de 2015, no estado do Tocantins.

Notou-se que a maior parte dos pacientes atendidos correspondia à idade de 70 a 79 anos, perfazendo um total de 45\%, seguido de pacientes com idade entre 60 e 69 anos, com 33\%, o que corrobora a estatística desta doença sendo mais prevalente em idosos.

Grande parte dos indivíduos atendidos era do estado do Tocantins, porém alguns moravam em cidades adjacentes do estado do Pará.

Com relação ao tempo entre o diagnóstico e o início do tratamento do câncer de próstata, verificou-se que houve predominância de 1 a 6 meses, tempo considerado como bom ou razoável, pois diminui a chand de evolução do quadro antes do início da terapia. Contudo, para $27,77 \%$ este tempo foi demasiadamente elevado (1 a 3 anos).

No que tange aos dados relacionados ao escore de Gleason houve uma predominância do nível 6 (41,66\%), indicando tumores de crescimento lento, porém verificou-se que metade da amostra tinha tumores de crescimento rápido, agressivos).

Os pacientes analisados apresentaram predominantemente estadiamento tipo II, $41,66 \%$ dos casos. O estadio III esteve presente em $38,88 \%$ e o IV em 13,88\%. Portanto, verificou-se que a maioria dos indivíduos estavam em fase avançada da doença, o que é considerado um mau prognóstico, o que pode apontar para uma falha nas campanhas estaduais realizadas para detecção precoce da doença ou uma demora no acesso deste indivíduos ao serviço do HGPP.

Verificou-se que foram realizadas diferentes formas de abordagem terapêutica, compatíveis com os vários estágios diferentes que a amostra apresentava. $\mathrm{O}$ tratamento por bloqueio hormonal $(\mathrm{BH})$ foi o mais utilizado com 
$39 \%$, o que converge com a maioria dos pacientes diagnosticados em fase avançada, o estadio III + estadio IV representavam $52,16 \%$. Posteriormente os tratamentos mais realizados foram a associação de $\mathrm{BH}+$ radioterapia com $28 \%$, associação entre $\mathrm{BH}+$ cirurgia (prostatectomia) + radioterapia com 19\% do total de pacientes pesquisados.

Para $36,11 \%$ dos pacientes a braquiterapia poderia ter sido aplicada, caso fosse disponibilizada no estado do Tocantins, o estadiamento era compatível. Caso esses pacientes tivessem sido diagnosticados precocemente, este contingente seria ainda maior.

A qualquer tempo que se considere, mais fundamentalmente em vigência de uma pandemia, esta proporção já significa valorosa ajuda para o funcionamento do HGPP, pois, por ser um tratamento ambulatorial e dispersar internamento, seria possível ofertar mais 52 dias/leito ano à sua demanda de pacientes. Em relação à gestão do Sistema Único de Saúde significaria a possibilidade de descentralização do tratamento oncológico do câncer de próstata e de outros tipos, pois poderia ser instalado com mais facilidade em outras localidades, diminuindo a dependência por encaminhamentos a outras cidades e estados, além dos custos com tratamento fora de domicílio, pagos aos pacientes transferidos.

Estudos como a de custos para a instalação de unidades de braquiterapia e quais cidades do estado do Tocantins têm infra-estrutura para recebê-las poderiam se complementar a este trabalho. Nota-se também a importância de outras análises para se verificar o tempo que os pacientes têm levado para serem admitidos na unidade de tratamento, pois este fator pode ser uma das causas da amostra deste trabalho se encontrar em fase avançada da doença. 


\section{REFERÊNCIAS}

AULA DE ANATOMIA. Sistema genital masculino. 2020. Disponível em: < https://www.auladeanatomia.com/novosite/pt/sistemas/sistema-genital/sistemagenital-masculino/>. Acesso em: 05 fev. 2020.

BITENCOURT, E. L. et al. Incidência de óbitos por neoplasias, segundo localização primária do tumor no estado do Tocantins de 2006 a 2015. Revista de Patologia do Tocantins, v. 5, n. 3, p. 5-11, 2018.

BRAGA, S. F. M. et al. Sobrevida e risco de óbito de pacientes após tratamento de câncer de próstata no SUS. Revista de Saúde Pública, v. 51, p. 46, 2017.

BRETAS, F. F. H. Câncer de próstata de alto risco. 2012. 28p. Disponível em: $<$ http://www.evidencias.com.br/pdf/publicacoes/8d76f14c59a42bcc1084ea9199a7 654e.pdf>. Acesso em: 19 nov. 2019.

BÓS, A. M. G.; BÓS, A. J. G. Determinantes na escolha entre atendimento de saúde privada e pública por idosos. Revista de Saúde Pública, São Paulo, v. 38, n. 1, p. 113-120, 2004.

CARLECH, H. S. Avaliação dos efeitos colaterais agudos em pacientes com câncer de próstata tratados com radioterapia conformacional em um hospital no leste de Minas. 2019. 56f. Dissertação (Mestrado em Ciências na Área de Tecnologia Nuclear - Aplicações) - Instituto de Pesquisas Energéticas e Nucleares, São Paulo, 2019.

CARNEVALE, F. C. et al. Prostatic artery embolization as a primary treatment for benign prostatic hyperplasia: preliminary results in two patients. Cardiovascular and interventional radiology, v. 33, n. 2, p. 355-361, 2010.

CASTRO, H. A. S. et al. Contribuição da densidade do PSA para predizer o câncer da próstata em pacientes com valores de PSA entre 2, 6 e 10, 0 ng/ml. Radiologia Brasileira, v. 44, n. 4, p. 205-209, 2011.

CAVALCANTI, V. Braquiterapia: bons resultados na luta contra o câncer - Portal Educação. Disponível em: <https://www.portaleducacao.com.br/conteudo/artigos leducacao/braquiterapia-bons-resultados-na-luta-contra-o-cancer/1298>. Acesso em: 19 jan. 2020.

CHOW, L. A.; NETO, F. S.; NEVES, D. P. Fatores que dificultam a adesão masculina ao exame preventivo do câncer de próstata em um município da microrregião do Bico do Papagaio - TO. Educandi \& Civitas, v. 1, n. 1, p. 21-42, 2018.

CLAUS, G. R.; JOHN, D. M. Etiology, Pathophysiology, Epidemiology and Natural History of Benign Prostatic Hyperplasia In: Walsh PC (ed.), Campbell's Urology. 2002. 
COLÉGIO BRASILEIRO DE RADIOLOGIA. Critérios de Adequação do ACR Braquiterapia permanente para câncer de próstata. Disponível em: $<$ http://www.cbr.org.br/wp-content/biblioteca-cientifica/v2/11 02.pdf $>$. Acesso em 10 mar. 2019.

DAMIÃO, R.; FIGUEIREDO, R.T.; DORNAS, M. C.; LIMA, D. S.; KOSCHORKE, M. A. B. Câncer de próstata. Rev HUPE, p. 80-86, 2015.

FAY, A. P. et al. Câncer de próstata: doença inicial e recorrência bioquímica. Disponível em: <https://sboc.org.br/images/diretrizes/diretrizes pdfs/Cancer de prostata.pdf>. Acesso em: 15 nov. 2019.

FILHO, R. T. F.; DAMIÃO, R. Câncer de próstata. $48^{\circ}$ Congresso do HUPE "Saúde do Homem". Disponível em: <http://revista.hupe.ueri.br/detalhe artigo.a sp?id=249>. Acesso em: 12 nov. 2019.

JEMAL, A. et al. Cancer statistics, 2005. CA: a cancer journal for clinicians, v. 55, n. 1, p. 10-30, 2005.

JUNIOR, V. J. Associação de radioterapia externa com braquiterapia de alta taxa de dose no tratamento do câncer de próstata. 2017. 61f. Dissertação (Mestrado em Ciências da Saúde) - Pontifícia Universidade Católica de Campinas, Campinas. 2017.

GACCI, M.; LAPINI, A.; SERNI, S.; LIVI, L. et al. Predictors of quality of life after radical treatment for prostate cancer. Urol Int, v. 80, p. 231. 2008.

HELPAP, B.; RINGLI, D.; TONHAUSER, J.; POSER, I.; BREUL, J.; GEVENSLEBEN, H.; SEIFERT, H. The Significance of Accurate Determination of Gleason Score for Therapeutic Options and Prognosis of Prostate Cancer. Pathology \& Oncology Research, v. 22, n. 2, p. 349-356, 2016.

HOSPITAL ISRAELITA ALBERT EINSTEIN. Braquiterapia prostática com sementes de I-125. 2016. Disponível em: <https://www.einstein.br/especialidades loncologia/exames-tratamentos/braquiterapia-prostatica>. Acesso em: 17 nov. 2019.

INCA - INSTITUTO NACIONAL DE CÂNCER JOSÉ ALENCAR GOMES DA SILVA Saúde do Homem. 2020. Disponível em: < https://www.inca.gov.br/campanhas/cancer-de-prostata/2020/saude-do-homem/>. Acesso em: 20 jan. 2021.

INCA - INSTITUTO NACIONAL DE CÂNCER JOSÉ ALENCAR GOMES DA SILVA. Informativo deteç̧ão precoce: monitoramento das ações de controle do câncer de próstata. Boletim Informativo Detecção Precoce, Rio de Janeiro, v. 8, n. 2. 2020.

INCA - INSTITUTO NACIONAL DE CÂNCER JOSÉ ALENCAR GOMES DA SILVA. Estimativa da incidência e mortalidade por câncer no Brasil 2018. Rio de Janeiro, 2018. 
INSTITUTO VENCER O CÂNCER. Tipos de câncer: câncer de próstata. 2018. Disponível em: <https://www.vencerocancer.org.br/tipos-de-cancer/cancer-deprostata-tipos-de-cancer/tratamento-9/>. Acesso em: 20 nov. 2019.

ISUP - INTERNATIONAL SOCIETY OF UROLOGICAL PATHOLOGY. 2020. Disponível em: <https://isupweb.org/isup/>. Acesso: 10 fev. 2020.

LEZE, E. Câncer de próstata. 2011. Disponível em: < http://www.fisiocirurgiauerj.org/defesas/2011/Eduardo\%20Leze Tese\%20-\%20nf .pdf>. Acesso em: 18 jan. 2020.

LIMA, J. R. Projeto e desenvolvimento de um dispositivo automático de controle e alimentação de tubos de titânio e fios de prata para a produção de sementes de iodo-125. 2016. 61f. Dissertação (Mestrado em Ciências na Área de Tecnologia Nuclear - Aplicações) - Instituto de Pesquisas Energéticas e Nucleares, São Paulo, 2016.

LÖBLER, R. et al. Avaliação do Escore de Gleason como fator prognóstico em pacientes com câncer de próstata em hormonioterapia. Revista Brasileira de Oncologia Clínica, v. 8, n. 27, 2012.

MADEIRA, L. R. Revisão sistemática entre abiraterona e enzalutamida no tratamento de pacientes com câncer de próstata metastático resistente à castração. 2017. 48f. Tese (Doutorado em Mestre em Ciências) - Universidade de São Paulo, São Paulo, 2017.

MARQUES, L. M. L. Avaliação das necessidades da braquiterapia contemporânea e os desafios de implementação do paradigma: cuidados de Radioterapia baseados no valor. 2019. 105f. Dissertação (Mestrado em Engenharia Biomédica) - Instituto Superior de Engenharia de Lisboa-Escola Superior de Tecnologia da Saúde de Lisboa.

MARTA, G. N.; HANNA, S. A.; SILVA, J. L. F. Braquiterapia de próstata: historicamente consagrada, eficaz e subutilizada. Diagn Tratamento, v. 16, n. 3 , p. 132-3, 2011.

MORI, R. R. Comparação dos critérios de agressividade do câncer de próstata diagnosticado por rastreamento no Brasil, em idades superior e inferior a 70 anos. 2016. 65f. Dissertação (Mestrado em Clínica Cirúrgica) Universidade de São Paulo, Faculdade de Medicina de Ribeirão Preto, 2016.

NEWSLETTER TDT. Os Técnicos de Diagnóstico e Terapêutica no Cancro da Próstata. 2015. Disponível em: <http://www.chln.pt/media/k2/attachments/newstdt INews TDT 21.pdf>. Acesso em: 20 dez. 2019.

OLIVEIRA, F. L. Avaliação dosimétrica de propostas de planejamento radioterápico para tratamento de mama e próstata. $85 \mathrm{f}$. 2015. Dissertação (Mestrado em Ciências) - Universidade Federal de Pernambuco, Recife, 2015. 
ONCOFISIO. Marcação com sementes radioativas ajuda no tratamento do câncer. 2016. Disponível em: <https://www.oncofisio.com.br/noticia/marcacaocom-sementes-radioativas-ajuda-no-tratamento-do-cancer/>. Acesso em: $05 \mathrm{dez}$. 2019.

PINHEIRO L. M. V. C. Contributo para o melhor conhecimento da Braquiterapia prostática: Morbilidade urinária e sexual. 2006. 196f. Tese (Doutorado em Ciências Médicas) - Faculdade de Ciências Médicas de Lisboa, Lisboa, 2006.

PORTAL DA UROLOGIA. Tudo sobre a vigilância ativa no câncer de próstata. 2017. Disponível em: <https://portaldaurologia.org.br/faq/tudo-sobre-a-vigilanciaativa-no-cancer-de-prostata/>. Acesso em: 05 dez. 2019.

PORTAL DA UROLOGIA. Nota oficial 2018 - Rastreamento do Câncer de Próstata. 2018. Disponível em: <https://portaldaurologia.org.br/medicos/destaquesbu/nota-oficial-2018-rastreamento-do-cancer-de-prostata/>. Acesso em: 02 dez. 2019.

SANDRINI, E. S. et al. Análise de margem de PTV para as técnicas de IMRT e VMAT em câncer de próstata utilizando IGRT. Revista Brasileira de Física Médica, v. 8, n. 2, p. 22-25, 2016.

SCHMIDT, A. Associação entre escore de Gleason e estadiamento, margens cirúrgicas livres e idade em pacientes com adenocarcinoma de próstata submetidos à prostatectomia radical. 51f. 2018. Monografia (Graduação em Medicina) - Universidade Federal da Fronteira Sul, Passo Fundo, RS, 2018.

SOBIN, L. H. Gallbladder Cancer. TNM Classification of Malignant Tumours, 6th edn. Sobin LH, Wittekind C. ed. 2002.

SOUZA, D. C. B. Desenvolvimento de um método para gerenciamento de rejeitos radioativos no laboratório de produção de fontes de iodo-125 utilizadas em braquiterapia. 2018. 130f. Dissertação (Mestrado em Ciências na Área de Tecnologia Nuclear - Aplicações) - Instituto de Pesquisas Energéticas e Nucleares, São Paulo, 2018.

SOUZA, C. D. Comparação entre métodos de fixação do iodo radioativo em substrato de prata para confecção de fontes utilizadas em braquiterapia. 2012. 58f. Dissertação (Mestrado em Ciências na Área de Tecnologia Nuclear Aplicações) - Instituto de Pesquisas Energéticas e Nucleares, São Paulo, 2012.

SOUSA, B. O. A. Incidência de câncer de próstata no estado do Tocantins entre 2001 e 2015. Revista de Patologia do Tocantins, v. 5, n. 2, p. 14-20, 2018.

VIANA, N. I. Correlação entre polimorfismos genéticos relacionados à hereditariedade, fatores hormonais e o câncer de próstata. 94f. 2017. Tese (Doutorado em Ciências) - Universidade de São Paulo, São Paulo, 2017. 
TANAGHO, E. A.; MCANINCH, J. W. Urologia geral de Smith. Grupo A-AMGH, 2010.

WILT, T. J. et al. Radical prostatectomy versus observation for localized prostate cancer. New England Journal of Medicine, v. 367, n. 3, p. 203-213, 2012.

ZIADA, A.; ROSENBLUM, M.; CRAWFORD, E. D. Benign prostatic hyperplasia: an overview. Urology, v. 53, n. 3, p. 1-6, 1999.

Núcleo de Ensino e Pesquisa - Serviço de Educação Permanente do Hospital Geral Público de Palmas, pesquisa número 09/2018. Dados coletados no período de fevereiro a Abril de 2019. 
7 APÊNDICE

\section{FORMULÁRIO DE PESQUISA}

Título do trabalho: ANÁLISE DOS PACIENTES PORTADORES DE CÂNCER DE PRÓSTATA, ATENDIDOS EM HOSPITAL DE REFERÊNCIA DO TOCANTINS, APTOS À BRAQUITERAPIA.

\begin{tabular}{|c|c|c|}
\hline \multicolumn{3}{|l|}{ NÚMERO DO PRONTUÁRIO } \\
\hline \multicolumn{3}{|l|}{ NOME DO PACIENTE } \\
\hline \multicolumn{3}{|l|}{ IDADE } \\
\hline \multicolumn{3}{|l|}{ PROCEDÊNCIA } \\
\hline \multicolumn{3}{|l|}{$\begin{array}{c}\text { TEMPO ENTRE O DIAGNÓSTICO E } \\
\text { INÍCIO DO TRATAMENTO }\end{array}$} \\
\hline \multicolumn{3}{|l|}{$\begin{array}{c}\text { TIPO HISTOLÓGICO DO CÂNCER DE } \\
\text { PRÓSTATA }\end{array}$} \\
\hline \multicolumn{3}{|l|}{ ESTADIAMENTO DA DOENÇA } \\
\hline \multicolumn{3}{|l|}{ TIPO DE TRATAMENTO REALIZADO } \\
\hline \multicolumn{3}{|l|}{ ONDE FOI REALIZADO O TRATAMENTO } \\
\hline $\begin{array}{c}\text { PODERIA TER SIDO TRATADO } \\
\text { ATRAVĖS DE BRAQUITERAPIA, } \\
\text { CONSIDERANDO O ESTADIAMENTO E } \\
\text { CARACTERIISTICAS CLÍNICAS DO } \\
\text { PACIENTE }\end{array}$ & SIM & NÃO \\
\hline
\end{tabular}




\section{INSTITUTO DE PESQUISAS ENERGÉTICAS E NUCLEARES}

Diretoria de Pesquisa, Desenvolvimento e Ensino

Av. Prof. Lineu Prestes, 2242 - Cidade Universitária CEP: 05508-000 Fone/Fax(0XX11) 3133-8908

SÃO PAULO - São Paulo - Brasil

http://www.ipen.br

O IPEN é uma Autarquia vinculada à Secretaria de Desenvolvimento, associada à Universidade de São Paulo e gerida técnica e administrativamente pela

Comissão Nacional de Energia Nuclear, órgão do

Ministério da Ciência, Tecnologia, Inovações e Comunicações. 